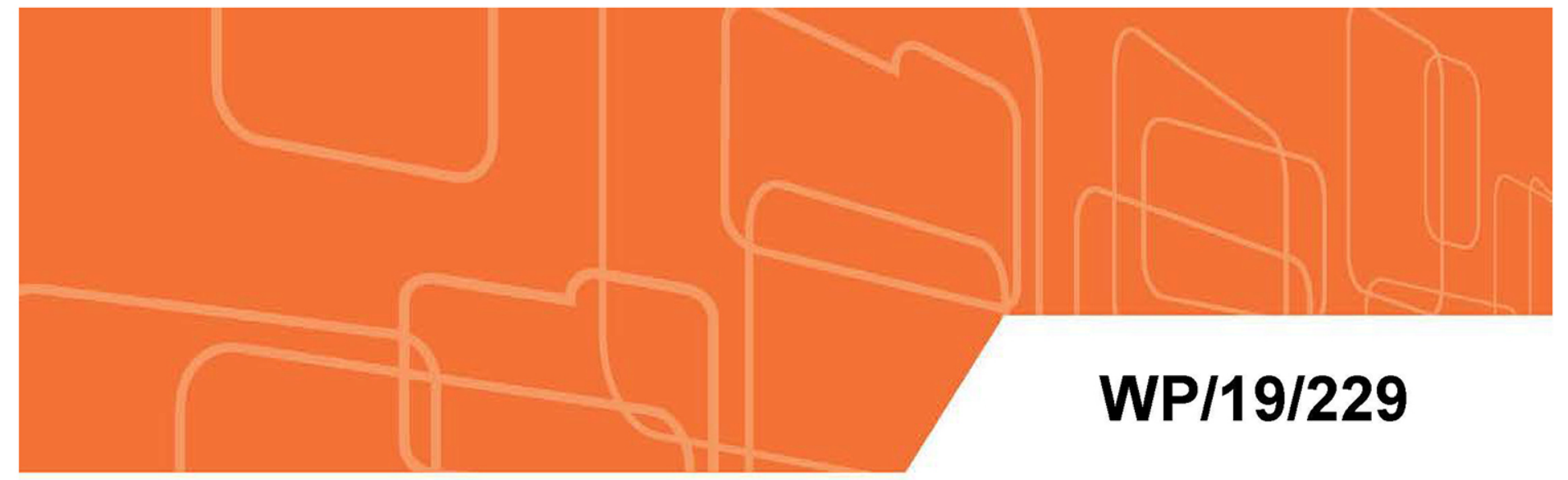

\title{
Achieving the Bank of Japan's Inflation Target
}

by Rahul Anand, Gee Hee Hong and Yaroslav Hul

IMF Working Papers describe research in progress by the author(s) and are published to elicit comments and to encourage debate. The views expressed in IMF Working Papers are those of the author(s) and do not necessarily represent the views of the IMF, its Executive Board, or IMF management. 


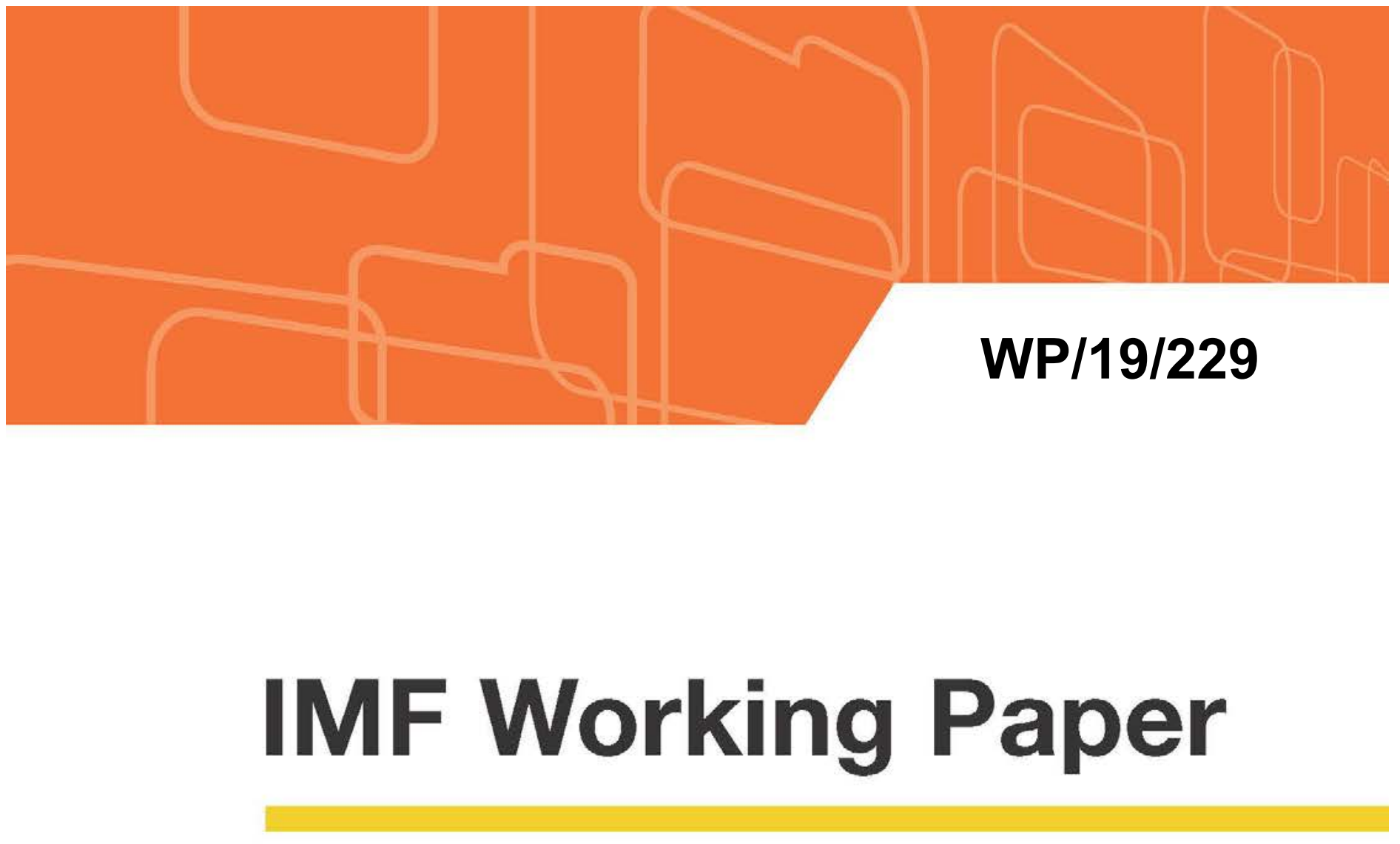

Achieving the Bank of Japan's Inflation Target

by Rahul Anand, Gee Hee Hong and Yaroslav Hul

IMF Working Papers describe research in progress by the author(s) and are published to elicit comments and to encourage debate. The views expressed in IMF Working Papers are those of the author(s) and do not necessarily represent the views of the IMF, its Executive Board, or IMF management.

I N T E R N A T I O N A L M O N E T A R Y F U N D 


\title{
IMF Working Paper
}

Asia and Pacific Department and Institute for Capacity Development

\section{Achieving the Bank of Japan's Inflation Target}

Prepared by Rahul Anand, Gee Hee Hong and Yaroslav Hul ${ }^{1}$

Authorized for distribution by Paul Cashin

November 2019

\section{IMF Working Papers describe research in progress by the author(s) and are published to elicit comments and to encourage debate. The views expressed in IMF Working Papers are those of the author(s) and do not necessarily represent the views of the IMF, its Executive Board, or IMF management.}

\begin{abstract}
The Bank of Japan has introduced various unconventional monetary policy tools since the launch of Abenomics in 2013, to achieve the price stability target of 2 percent inflation. In this paper, a forward-looking open-economy general equilibrium model with endogenously determined policy credibility and an effective lower bound is developed for forecasting and policy analysis (FPAS) for Japan. In the model's baseline scenario, the likelihood of the Bank of Japan reaching its 2 percent inflation target over the medium term is below 40 percent, assuming the absence of other policy reactions aside from monetary policy. The likelihood of achieving the inflation target is even lower under alternative risk scenarios. A positive shock to central bank credibility increases this likelihood, and would require less accommodative macroeconomic policies.
\end{abstract}

JEL Classification Numbers: E52, E58, F47, O23

Keywords: Inflation targeting, forecasting, fan charts, zero lower bound, FPAS Authors’ E-Mail Addresses: ranand@,imf.org; ghong@imf.org; yhul@,imf.org

\footnotetext{
${ }^{1}$ The authors are grateful to Patrick Blagrave, Odd Per Brekk, Paul Cashin, Mariana Colacelli, Wataru Hirata, Yosuke Kido, Charles Kramer, Dirk Muir, Kazuaki Miyachi, Scott Roger, Todd Schneider, Piyaporn Sodriwiboon, Niklas Westelius, colleagues in the IMF Asia and Pacific Department and Institute for Capacity Development, and seminar participants at the Bank of Japan and Japanese Ministry of Finance for helpful comments and discussions.
} 


\section{Table of Contents}

Page

ABSTRACT $\underline{2}$

I. INTRODUCTION $\underline{4}$

II. BACKGROUND

A. Persistently Low Inflation and Inflation Expectations

B. The Existence of an Effective Lower Bound (ELB)

III. THE MODEL

A. General Features

B. Overview of Japan's QPM

IV. PARAMETRIZATION OF THE MODEL AND MODEL PROPERTIES

A. Calibration

B. Impulse Response Functions

V. RESULTS

A. Baseline Results

B. Scenarios

VI. CONCLUSION

References

\section{FIGURES}

1. Impulse Response Functions in Response to a Cost-push Shock $\underline{18}$

2. Impulse Response Functions in Response to a Negative Oil Price Shock $\underline{19}$

3. Impulse Response Functions in Response to a Discretionary Fiscal Impulse $\underline{20}$

4. Baseline Projections for CPI Inflation and Real GDP Growth $\underline{21}$

5. Baseline Projections for Real GDP and Real Output Gap $\underline{22}$

6. Composition of Real Output Gap $\underline{22}$

7. Baseline: Composition of Headline Inflation $\underline{23}$

8. Baseline: Decomposition of Core Inflation $\underline{23}$

9. Baseline: Nominal and Real Interest Rate $\underline{24}$

10. Baseline: Fan Charts for Headline and Core CPI Inflation 25

11. Baseline: Fan Charts for Real GDP Growth and Unemployment Rate $\underline{25}$

12. Comparison of Scenarios: Credible vs. Imperfectly Credible Central Bank $\underline{27}$

\section{TABLES}

1. Comparison Across Different Scenarios. $\underline{28}$

\section{APPENDICES}

I. Evolution of the Bank of Japan's Monetary Policy During Abenomics $\underline{32}$

II. Calibration of Parameters $\underline{36}$ 


\section{INTRODUCTION}

In 2013, the new government of Prime Minister Shinzo Abe announced an ambitious policy framework often referred to as "Abenomics." The three-arrows of Abenomics called for a coordinated policy effort by the Bank of Japan (BoJ) and the government to jumpstart the economy and create sustained growth synergies through bold structural reforms (Cabinet Office and Bank of Japan (2013)2, IMF (2013), IMF (2014)). Accordingly, on January 22, 2013 , the BoJ announced a new monetary policy framework where a 2 percent inflation target, measured as the year-on-year rate of change in headline consumer price index (CPI), became the price stability mandate. The objective was to pull Japan out of deflation which had afflicted the country for two decades.

The newly-introduced "price stability target" is the inflation rate that the Bank judges to be consistent with price stability on a sustainable basis. The Bank recognizes that the inflation rate consistent with price stability on a sustainable basis will rise as efforts by a wide range of entities toward strengthening competitiveness and growth potential of Japan's economy make progress. Based on this recognition, the Bank sets the "price stability target" at 2 percent in terms of the year-on-year rate of change in the consumer price index (CPI) -- a main price index. (The "Price Stability Target" under the Framework for the Conduct of Monetary Policy, January 22, 2013, Bank of Japan)

Despite the BoJ's efforts to raise inflation expectations, inflation and inflation expectations remained stubbornly below 2 percent, which prompted the BoJ to introduce additional unconventional monetary measures and to modify its monetary policy framework over time. On April 4, 2013, the BoJ introduced the "quantitative and qualitative monetary easing" (QQE) and entered a new phase of monetary easing both in terms of quantity and quality, by doubling the monetary base and purchasing assets including the Japanese government bonds (JGBs), exchange-traded funds (ETFs) and Japan real estate investment trusts (J-REITs). On October 31, 2014, the purchase amount of JGBs increased from an annual pace of about $¥ 50$ trillion to $¥ 80$ trillion. In January 2016, the negative interest rate policy was introduced. Later that year, the BoJ introduced a new framework of "QQE with yield curve control" which consisted of two new components in addition to QQE: (1) "yield curve control" in which the BoJ will control short-term and long-term interest rates and (2) inflation-overshooting commitment in which the BoJ commits to expanding the monetary base until the year-onyear rate of increase in the observed CPI exceeds the price stability target of 2 percent and stays above the target in a stable manner. ${ }^{3}$

Six years into Abenomics, the possibility of achieving the 2 percent inflation target over the medium-term is still being debated. Headline inflation projections conducted by several institutions, including the BoJ, expect that the 2 percent inflation target is not likely to be met within the projection horizon. In previous years, the BoJ has delayed the timeline to meet the

\footnotetext{
2 Joint Statement of the Government and the Bank of Japan on Overcoming Deflation and Achieving Sustainable Economic Growth, January 22, 2013 (https://www.boj.or.jp/en/announcements/release 2013/k130122c.pdf).

${ }^{3}$ See Appendix I for the timeline of monetary policy initiatives introduced by the Bank of Japan since the launch of Abenomics. Details on the new framework after a comprehensive assessment in 2016 can be found here: https://www.boj.or.jp/en/announcements/release 2016/k160921a.pdf.
} 
2 percent inflation target and the most recent projection shows that the target will be met outside of the projection horizon (July 2019, Outlook for Economic Activity and Prices). Inflation expectations, which were temporarily lifted with the announcement of Abenomics, are still stubbornly low and below the 2 percent target. A prolonged period of aggressive monetary easing raises concerns about financial stability and potential side-effects due to suppressed profitability of the banking sector. Regardless, the BoJ remains committed to achieving the price stability mandate. ${ }^{4}$

Against this backdrop, the purpose of this paper is to construct for Japan a model-based forecasting framework called the Forecasting and Policy Analysis System (FPAS) that is consistent with the inflation target set by the central bank. FPAS is one of many models designed for policymakers of those central banks that have adopted an inflation targeting regime (Coats, Laxton, and Rose, 2003; Anand et al., 2014; Benes et al., 2017). One of the key elements of FPAS is a quarterly projection model (QPM), which is a forward-looking open-economy calibrated gap model that helps to generate a medium-term policy path and projections consistent with the policy targets defined under the inflation targeting regime. In an ideal setting, an FPAS framework serves as a device to organize thoughts and data coherently in the form of a baseline assessment, assess the balance of risks to the baseline projections and describe the nature of policy response to various kinds of shocks (Berg, Karam, and Laxton, 2006a and 2006b).

In addition to the basic characteristics of QPM, we introduce several features into the model that are characteristic of Japan's economy and allow us to replicate Japan-specific stylized facts. First, given the persistently low inflation, and reflecting the challenges which monetary policy in Japan faces in lifting the inflation expectations, we model the credibility of the central bank. In reality, the credibility of the central bank in achieving the inflation objective depends on policies beyond monetary policy. For simplicity, we assume in this model that the credibility is conditional on the central bank's historical record of reaching the inflation target. This, in turn, feeds into the formation of inflation expectations. For instance, with a fully credible central bank, inflation expectations are anchored at the central bank's inflation target. For a central bank with imperfect credibility, on the other hand, the lower is the credibility the more backward-looking are inflation expectations, leading to a deviation of inflation expectations from the inflation target. Second, we introduce an effective lower bound constraint for the nominal policy rate. Third, we introduce a simplified description of the fiscal sector to reflect aggregate macro-fiscal linkages. Finally, we decompose headline inflation into food, energy and core inflation to better capture the different dynamics of each of inflation components.

Using this framework, we assess the medium-term projections and quantify the likelihood of achieving the BoJ's 2 percent inflation target under several potential risk scenarios. The baseline scenario assumes an imperfectly credible central bank. We expand the baseline analysis by introducing the following four scenarios: (i) a central bank with perfect

\footnotetext{
4 "The Bank of will continue with "Quantitative and Qualitative Monetary Easing (QQE) with Yield Curve Control," aiming to achieve the price stability target of 2 percent, as long as it is necessary for maintaining that target in a stable manner. It will continue expanding the monetary base until the year-on-year rate of increase in the observed consumer price index (CPI, all items less fresh food) exceeds 2 percent and stays above the target in a stable manner. (Statement of Monetary Policy, July 30, 2019, Bank of Japan)"
} 
credibility; (ii) a temporary sharp appreciation of the Japanese yen; (iii) a temporary sharp increase in the sovereign risk premium; and (iv) a temporary world oil price decrease. Under each scenario, we quantify the likelihood of achieving the BoJ's 2 percent target using fan charts. Fan charts are constructed using a two-piece normal distribution to allow for asymmetric balance of risks around the baseline scenario (Blix and Sellin (1998); Kannan and Elekdag (2009)).

Our findings can be summarized as follows. Using fan chart analysis, headline inflation and core inflation will likely remain below the BoJ's 2 percent inflation target over the mediumterm, under the baseline scenario. The probability of headline inflation and core inflation reaching 2 percent is close to one third, 37.3 and 35.5 percent, respectively. To realize this path, the present accommodative monetary policy stance should continue, ensuring that the real interest rate remains below zero and a positive output gap persists. The likelihood of reaching the 2 percent target increases when the credibility of central bank increases. With a perfectly credible central bank, the probability of reaching the 2 percent target over the medium-term is around 45 percent for both headline and core inflation. ${ }^{5}$ Under alternative scenarios introducing various adverse shocks, the probabilities of achieving the inflation target decline.

The paper is organized as follows. In Section II, we describe some important aspects of the Japanese economy to be highlighted in the model. In Section III, we lay out an overview of the FPAS model for Japan. Section IV describes the parametrization of the model and model properties. Section V shows results under the baseline and alternative scenarios, with fan charts quantifying the likelihood of achieving the target and the risks associated with it. Finally, in Section VI, we conclude with some policy implications.

\section{BACKGROUND}

\section{A. Persistently Low Inflation and Inflation Expectations}

Japan's economy entered a period of low growth and deflation after the burst of the asset bubble in the early 1990s. Since the launch of Abenomics, however, growth momentum returned, corporate profits rose to recordhigh levels and many Japanese workers entered the labor market. Despite the revived growth momentum, inflation (measured by either GDP deflator or CPI) is still at low level. Headline CPI rose temporarily above 2 percent in 2014, following the consumption tax rate increase. In 2016, with lower oil prices, CPI went into negative territory.

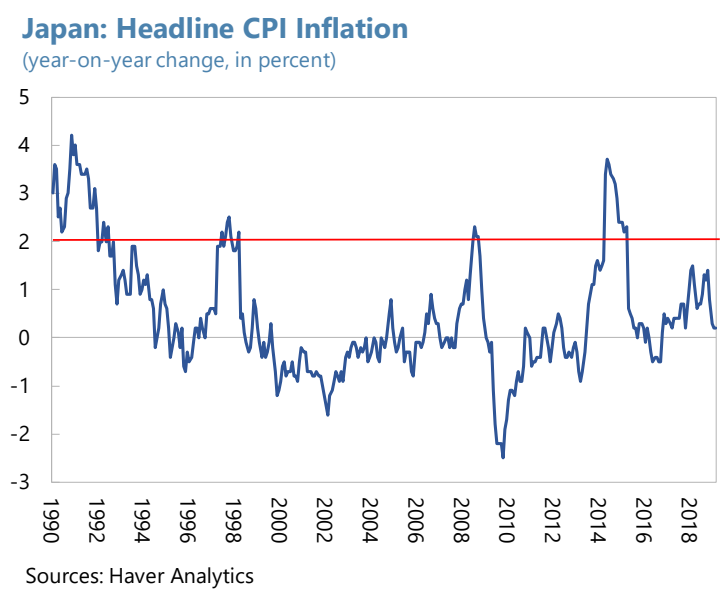

\footnotetext{
${ }^{5}$ While it is beyond the scope of this paper, a comprehensive policy package that highlight the coordination of fiscal and monetary policy with structural reforms would also increase the chance of reaching the inflation target (IMF 2016, 2017, 2018, Colacelli and Fernandez-Corugedo (2018)).
} 
While inflation rate has returned to positive territory since 2017 , it has fallen short of the two percent inflation target.

Many studies have attempted to assess the effect of the Bank of Japan's QQE policy on inflation and inflation expectations. So far, the results are mixed. Kaihatsu and Nakajima (2015) shows an upward movement of the trend inflation following the QQE policy. Also, Kamada and others (2015) show that the QQE strengthened the anchor of long-term inflation expectations, with higher expected inflation and less dispersion. On the other hand, Nakazono (2016) shows that the effects of the QQE on inflation expectations were limited, based on various survey data for households, firms, professionals and market participants.

In its 'Outlook for Economic Activity and Prices' report published in July 2018, the Bank of Japan updated its growth and inflation projections where, for the first time, the 2 percent inflation target was projected to be met outside of the forecast horizon. Deeply engrained deflationary mindset and backward-looking formation of inflation expectations were mentioned as the main obstacles for the Bank of Japan to lift and re-anchor inflation expectations at 2 percent. Going forward, adverse demographic trends with Japan's rapidly declining and aging population will continue to weigh on growth and inflation prospects. Official projections anticipate the population will age and shrink by over 25 percent in the next 40 years, which will depress growth, productivity and price pressures (see IMF 2016, 2017, 2018, and Colacelli and Fernandez-Corugedo (2018)).
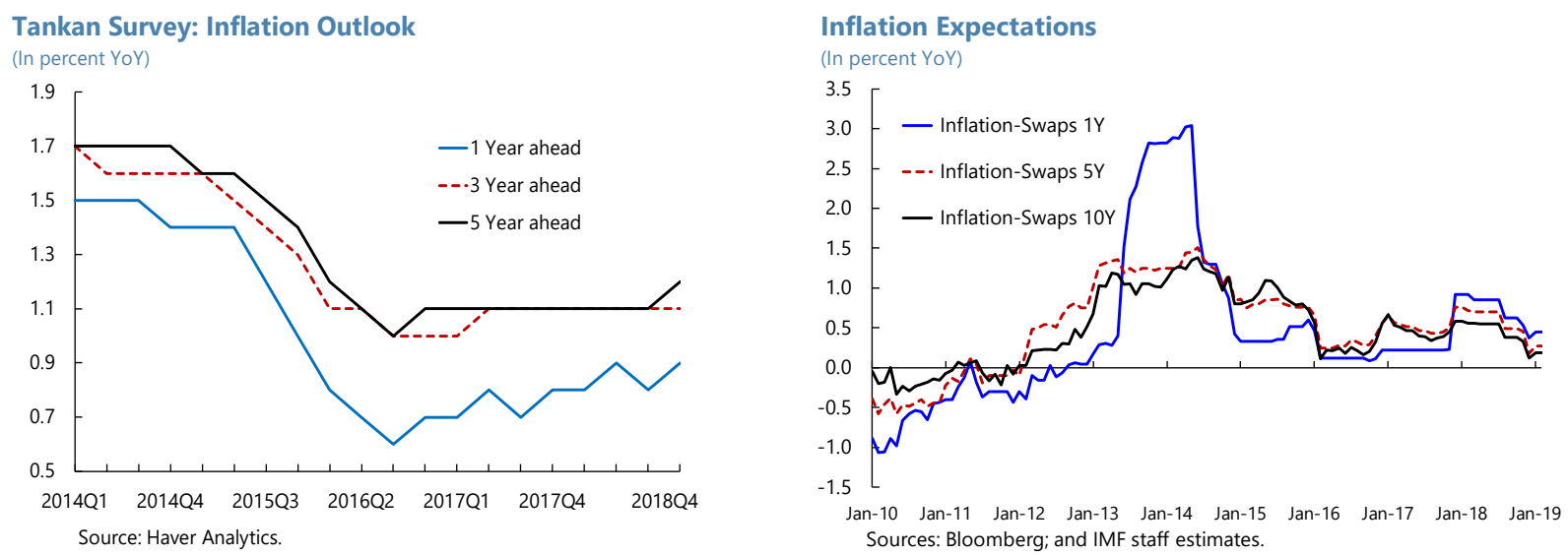


\section{B. The Existence of an Effective Lower Bound (ELB)}

Japan's policy rate has been constrained at the zero-lower bound since the late 1990s, when many financial institutions failed after the collapse of the bubble economy and the economy fell into deflation.

To overcome deflation, the Bank of Japan pioneered unconventional monetary policy, nearly two decades before all other central banks. In 1999, the Bank of Japan introduced the zerointerest rate policy (ZIRP), in which the overnight interest rate was guided to "as low as possible." In 2001, the Bank introduced quantitative easing (QE) by setting financial institutions' current account balances at the Bank, rather than the short-term interest rate, as its main operating target.

Since 2013, the BoJ's price mandate has been to target the headline inflation rate. In January 2016 the BoJ also adopted negative interest rate poliy, following the footstep of the European Central Bank and Swiss National Bank. The BoJ's negative interest rate policy adopted a three-tier system in which a positive interest rate or a zero-interest rate will be applied to current account balances up to certain thresholds, in order to make sure that financial institutions' functions as financial intermediaries would not be impaired. The negative rates were to be charged to new transactions (macro add-on balance) that add to a marginal increase in the current account balance at minus 0.1 percent. ${ }^{6}$ Monetary policy framework was further revised later in 2016, by introducing yield curve control (YCC) and including an overshooting commitment, while maintaining the negative interest rate policy.

\section{THE MODEL}

In this section, we outline the Quarterly Projection Model (QPM) for Japan and discuss how selected features of the Japan's economy are reflected in the model equations.

\section{A. General Features}

The model for Japan falls into the family of small open-economy models a-la Berg et al. (2006a, 2006b), which are commonly used in the context of Forecasting and Policy Analysis Systems (FPAS) in numerous central banks around the world (most notably inflation targeting central banks). ${ }^{7}$ QPM for Japan is a semi-structural gap model, which is based on a New-Keynesian paradigm (with its emphasis on nominal and real rigidities as well as rational expectations) and has characteristics explicitly derived from microeconomic foundations. However, compared to DSGE-type models, the

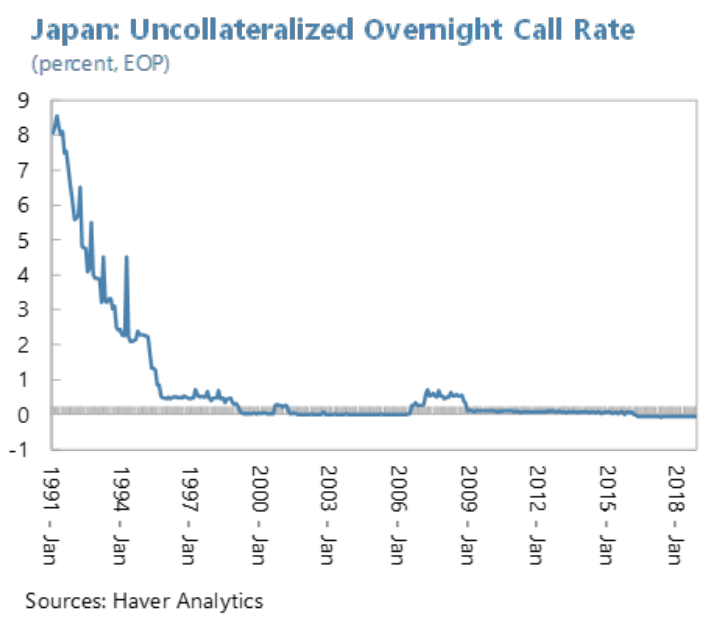

\footnotetext{
${ }^{6}$ For some preliminary impact of Japan's negative interest rate policy, see Hong and Kandrac (2018).

${ }^{7}$ Among others, see Benes et al (2017) for India and Amarasekara et al. (2018) for Sri Lanka.
} 
QPM is not completely micro-founded, and instead features also various ad-hoc extensions to be able to better explain the data and replicate desired empirical properties. This makes the model fundamentally consistent with the economic theory but at the same time flexible enough to incorporate expert views and judgments, which is important for practical monetary policy analysis and forecasting.

One of the key features of the QPM approach is an endogenously-determined monetary policy interest rate. Following a certain reaction function, a central bank sets its policy rate in response to the movements in expected inflation and other variables in a way that enables inflation to return to the announced target over the medium term. It embodies the basic principle that the fundamental role for monetary policy is to provide an anchor for inflation and inflation expectations.

The Japan model is used for producing mutually-consistent medium-term projections of main macroeconomic variables and assessing endogenous path for the monetary policy actions consistent with inflation going back to the target and economy converging to equilibrium. The model is also essential for quantifying macroeconomic risks, conducting counter-factual scenario analysis, and evaluating different policy options.

\section{B. Overview of Japan's QPM}

The QPM model for Japan is designed to capture the selected important characteristics of the Japanese economy. Consequently, the model includes several blocks of behavioral equations: (1) an aggregate demand block, with a modified IS curve in its core, which describes the development of output gap and relates it to the real monetary conditions in the economy, and to the developments in the fiscal and foreign sectors; (2) a price setting block, modelled by individual Phillips curves for the three components of headline inflation (core, food, and energy), that relate development in domestic prices with inflation expectations, imported inflations, and approximated real marginal costs of producers; (3) a version of an uncovered interest rate parity condition, which determines the no-arbitrage exchange rate that ensures equality between risk-adjusted returns in domestic and foreign capital markets; (4) an imperfectly credible monetary policy that uses a Taylor-type rule for setting the nominal interest rate, which is constrained from below by an effective lower bound (ELB); (5) a simplified fiscal block, modelling basic debt dynamics and a fiscal impulse which feeds into aggregate demand; and (6) a fully exogenous foreign sector.

The chart below describes the key behavioral relationships of each block. 
Japan QPM: Broad Overview

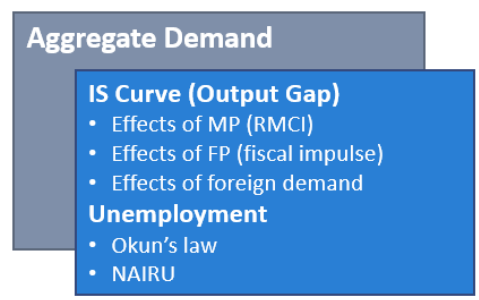

Fiscal Policy

Simple debt dynamics

Effect of debt on risk premium

Demand effects (fiscal impulse)

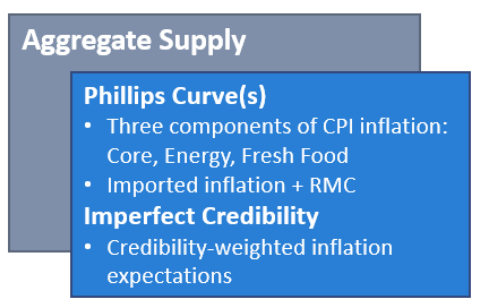

\section{Monetary Policy}

Taylor-type rule

Endogenous credibility

Effective zero lower bound (ZLB)

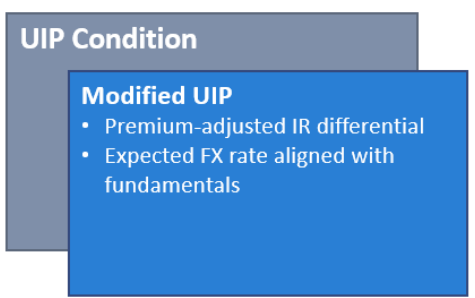

\section{Foreign Sector}

GPM7-based

- Import-weighted REER

- Export-weighted effective foreign

output gap

- US interest rates and inflation

- World oil and food prices

\section{Aggregate demand}

The aggregate demand in the model is proxied by output gap $(\hat{y})$, which is governed by the following process:

$$
\hat{y}_{t}=\beta_{1} \hat{y}_{t-1}+\beta_{2} \hat{y}_{t+1}+\beta_{3} R M C I_{t}+\beta_{4} \hat{y}_{t}^{*}+\beta_{5} f i m p_{t}+\varepsilon_{t}^{\hat{y}}
$$

It is derived from a New Keynesian IS curve, and incorporates a backward-looking specification (Goodhart and Hofmann, 2005; Fuhrer and Rudebusch, 2004). As such, the output gap is determined by: its lagged value (proxying consumers' habit formation property), a model-consistent expectation of output gap (proxying consumption smoothing behavior by households) and a real monetary conditions index (RMCI), defined as a combination of the real interest rate gap and the real effective exchange rate gap (see Eq. 2) .

$$
R M C I_{t}=\lambda \hat{r}_{t}+(1-\lambda)\left(-\hat{z}_{t}^{R E E R}\right)
$$

Additionally, the output gap is influenced by foreign demand, $\hat{y}_{t}^{*}$, and fiscal impulse, fimp, which are defined below in the fiscal block.

Okun's law pins down the relationship between output gap and an unemployment rate:

$$
\hat{u}_{t}=\gamma_{1} \hat{u}_{t-1}+\gamma_{2} \hat{y}_{t}+\varepsilon_{t}^{\widehat{u}}
$$

\section{Inflation dynamics}

The overall headline CPI inflation is decomposed into three components - core, energy, and fresh food: 


$$
\pi_{t}=\theta_{1} \pi_{t}^{\text {core }}+\theta_{2} \pi_{t}^{e n}+\left(1-\theta_{1}-\theta_{2}\right) \pi_{t}^{f f}+\varepsilon_{t}^{\pi}
$$

Here, $\theta_{1}$ is a composite weight of core components in the CPI basket, $\theta_{2}$ - composite weight of energy components, and $\varepsilon_{t}^{\pi}$ is a residual term to allow for discrepancies in the data (e.g. because the weights are not constant over time).

The processes for inflation components are modelled by separate equations, reflecting different dynamics that these inflation components exert.

Core inflation is governed by a Phillips curve (Eq. 5) which features a backward-looking component $\left(\pi_{t-1}^{\text {core }}\right)$, credibility-weighted headline inflation expectations $\left(\pi_{t}^{E w}\right)$, direct passthrough from imported foreign inflation (proxied by the change in real effective exchange rate gap, $\left.\Delta \hat{z}_{t}^{R E E R}\right)$, core real marginal costs $\left(r m c_{t}^{\text {core }}\right)$, and a core inflation cost-push shock $\left(\varepsilon_{t}^{\pi^{\text {core }}}\right)$.

$$
\pi_{t}^{\text {core }}=\alpha_{\text {core }} \pi_{t-1}^{\text {core }}+\left(1-\alpha_{\text {core }}\right) \pi_{t}^{E w}+\alpha_{2} \Delta \hat{z}_{t}^{R E E R}+\alpha_{3} r m c_{t}^{\text {core }}+\varepsilon_{t}^{\pi^{\text {core }}}
$$

Core real marginal costs are driven by the cost of domestic (approximated by output gap, $\hat{y}_{t}$ ) and foreign (approximated by real effective exchange rate gap, $\hat{z}_{t}^{R E E R}$ ) factors of production.

$$
r m c_{t}^{\text {core }}=\alpha_{r m c} \hat{z}_{t}^{R E E R}+\left(1-\alpha_{r m c}\right) \hat{y}_{t-1}
$$

The dynamics of food and energy inflations is similar to the dynamics of core inflation, but they are affected by different import prices (i.e. world oil price in case of energy inflation component, and world food price in case of fresh food inflation component), and different real marginal costs (approximated by real world oil price gap, $\hat{z}_{t}^{O I L}$, and real world food price gap, $\hat{z}_{t}^{F O O D}$, accordingly):

$$
\begin{gathered}
\pi_{t}^{e n}=\alpha_{e n} \pi_{t-1}^{e n}+\left(1-\alpha_{e n}\right) \pi_{t}^{E w}+\alpha_{4} \Delta \hat{z}_{t}^{O I L}+\alpha_{5} \hat{z}_{t}^{O I L}+\varepsilon_{t}^{\pi^{e n}} \\
\pi_{t}^{f f}=\alpha_{f f} \pi_{t-1}^{f f}+\left(1-\alpha_{f f}\right) \pi_{t}^{E w}+\alpha_{6} \Delta \hat{z}_{t}^{F O O D}+\alpha_{7} \hat{z}_{t}^{F O O D}+\varepsilon_{t}^{\pi^{f f}}
\end{gathered}
$$

For simplicity, we assume that all inflation components converge to the same inflation target $^{8}$, and therefore inflation expectations' term is identical in all three equations (i.e. $\left.\pi_{t}^{E w}\right){ }^{9}$

\footnotetext{
${ }^{8}$ This is, however, not the case historically, whereby core inflation is persistently lower than the other two components.

${ }^{9}$ In Fuhrer (2017), fresh food and energy price inflation is described by a simple AR process.
} 
Inflation expectations are governed by the process which is affected by the credibility of the central bank, credib $_{t}$ (the higher is the credibility the more forward-looking are inflation expectations ${ }^{10}$ ), and the inflation expectations "bias", bias : $^{\text {: }}$

$$
\pi_{t}^{E w}=\operatorname{credib}_{t} \cdot E_{t} \pi_{t+1}^{\text {yearly }}+\left(1-\operatorname{credib}_{t}\right) \cdot \pi_{t-1}^{\text {yearly }}+\text { bias }_{t}+\varepsilon_{t}^{\pi^{E w}}
$$

Central bank credibility. The credibility of the central bank $\left(\right.$ credib $\left._{t}\right)$ is a stock variable, taking values between 0 and 1. It is an AR(1) process driven by the credibility signal $\left(\xi_{t}^{\text {signal }}\right)$, which in turn is inferred from the past ability of the central bank in achieving the inflation target.

$$
\begin{gathered}
\text { credib }_{t}=\alpha_{\text {cred }} \cdot \text { credib }_{t-1}+\left(1-\alpha_{\text {cred }}\right) \cdot \xi_{t}^{\text {signal }}+\varepsilon_{t}^{\text {credib }} \\
\xi_{t}^{\text {signal }}=\frac{\left(\epsilon_{t}^{\text {bad }}\right)^{2}}{\left(\epsilon_{t}^{\text {bad }}\right)^{2}+\left(\epsilon_{t}^{\text {good }}\right)^{2}}+\varepsilon_{t}^{\xi^{\text {signal }}} \\
\epsilon_{t}^{\text {bad }}=\left\{\begin{array}{cl}
0, & \text { if } \pi_{t-1}^{4} \leq 0 \\
\pi_{t-1}^{4}-0, & \text { if } \pi_{t-1}^{4}>0
\end{array} \quad \epsilon_{t}^{\text {good }}=\left\{\begin{array}{cc}
0, & \text { if } \pi_{t-1}^{4} \geq \pi^{\text {tar }} \\
\pi^{t a r}-\pi_{t-1}^{4}, & \text { if } \pi_{t-1}^{4}<\pi^{\text {tar }}
\end{array}\right.\right.
\end{gathered}
$$

In technical terms, the credibility signal $\xi_{t}^{\text {signal }}$ evolves depending on the previous period's realization of year-on-year headline inflation, $\pi_{t-1}^{4}$, and is subject to a shock, $\varepsilon_{t}^{\xi^{\text {signal }}}$.

We consider three states of the world: (i) when previous period's inflation is at or below zero $\left(\pi_{t-1}^{4} \leq 0\right)$, (ii) when it is at or above the target $\left(\pi_{t-1}^{4} \geq \pi^{t a r}\right)$, and (iii) when it is in between 0 and $\pi^{\text {tar }}$. In the case (i) the economic agents extract a zero-credibility signal, which means that they perceive central bank's actions in previous period as perfectly non-credible. In the case (ii) they extract a credibility signal equal to 1 , which means that they perceive central bank's behavior in previous period a perfectly credible. Finally, in the case (iii) the credibility signal depends on proximity of past inflation to the target - the closer it is to the target the higher is the signal.

Note, that because the central bank's overall credibility $\left(\right.$ credib $\left._{t}\right)$ is a stock variable, it is accumulated or depleted over time, and generally is only marginally affected by per-period credibility signal $\xi_{t}^{\text {signal }}$. In fact, the higher is the persistence of the credibility stock (i.e. the coefficient $\alpha_{\text {cred }}$ ), the less central bank's credibility (and accordingly inflation expectations) is affected by per-period signal. This has an important policy implication. If the central bank's initial stock of credibility is low, given everything else equal, the monetary policy needs to be relatively more aggressive to achieve its inflation objective, compared to the case with the central bank having a high stock of credibility.

\footnotetext{
10 The credibility-weighted inflation expectations are modelled in a similar way as in Argov et al (2007) and Alichi et al. (2009).
} 
Inflation expectations "bias". In forming inflation expectations, we also introduce the expectations bias of the economic agents:

$$
\text { bias }_{t}=\beta_{\text {bias }} \cdot\left(\text { credib }_{t} \cdot \pi^{\text {tar }}+\left(1-\operatorname{credib}_{t}\right) \cdot 0-\pi^{\text {tar }}\right)
$$

For a perfectly credible central bank $\left(\right.$ credib $\left._{t}=1\right)$, the bias is zero. In all other cases, there is a negative bias by the economic agents towards inflation, which weighs down on inflation expectations.

\section{Monetary policy reaction function}

The reaction function of the monetary authorities in the model consists of two parts - the policy interest rate $i_{t}$ either (i) follows a Taylor-type rule (in normal times), in which case it traces the unconstrained interest rate $i_{t}^{U N C}$, or (ii) it equals to $i^{\text {floor }}$, which is an effective lower bound and constraints the policy rate from below. This is implemented in the model with the following equation:

$$
i_{t}=i^{\text {floor }}+0.5 \cdot\left(i_{t}^{U N C}-i^{\text {floor }}+\frac{\left(i_{t}^{U N C}-i_{\text {floor }}\right)^{2}}{\sqrt{\left(i_{t}^{U N C}-i^{\text {floor }}\right)^{2}}}\right)
$$

When not at ELB, the central bank adheres to a Taylor-type rule whereby by setting the policy interest rate it reacts to expected inflation deviation from the target and to deviation of output from the potential:

$$
i_{t}^{U N C}=\alpha_{i n t} \cdot i_{t-1}+\left(1-\alpha_{i n t}\right) \cdot\left(i_{t}^{\text {neutral }}+1 \cdot\left(\pi_{t+3}^{E w}-\pi_{t}^{t a r}\right)+\alpha_{8} \cdot \hat{y}_{t}\right)+\varepsilon_{t}^{i}
$$

The central bank has a preference for smooth adjustments in the policy rate rather than abrupt changes, therefore the unconstrained reaction function is persistent (i.e. features a lagged term). Furthermore, the monetary policy can choose to deviate from the "rule" via a discretionary decision captured by the monetary policy shock $\left(\varepsilon_{t}^{i}\right)$.

In the absence of any discretion and any inflationary or demand pressures, the policy rate is assumed to converge to the nominal neutral interest rate $\left(i_{t}^{n e u t r a l}\right)$, which is the sum of equilibrium real interest rate $\left(\bar{r}_{t}\right)$, and inflation expectations $\left(\pi_{t+3}^{E w}\right)$.

$$
i_{t}^{\text {neutral }}=\bar{r}_{t}+\pi_{t+3}^{E w}
$$

\section{Uncovered Interest Parity (UIP) Condition}

We model a modified version of the Uncovered Interest Parity (UIP) condition. It pins down the relationship between expected exchange rate depreciation and interest rate differential and is further adjusted to include a long-term risk premium $\left(\sigma_{t}\right)$, a transitory risk premium $\left(\sigma_{t}^{T}\right)$, and a UIP shock $\left(\varepsilon_{t}^{S}\right)$ to account for the observed data. 


$$
s_{t}=s_{t+1}^{E}-\frac{i_{t}-i_{t}^{*}-\sigma_{t}-\sigma_{t}^{T}}{4}+\varepsilon_{t}^{s}
$$

The expected exchange rate is further modified to reflect the observed real-life persistence in the Japanese yen. For this we weigh the pure model-consistent exchange rate expectations $E_{t} s_{t+1}$ by a backward-looking component.

$$
\begin{gathered}
s_{t+1}^{E}=\alpha_{U I P} \cdot E_{t} s_{t+1}+\left(1-\alpha_{U I P}\right) \cdot\left(s_{t-1}+2 \cdot \Delta \bar{s}_{t} / 4\right) \\
\Delta \bar{s}_{t}=\Delta \bar{z}_{t}-\pi^{*, t a r}+\pi_{t}^{t a r}
\end{gathered}
$$

The backward-looking element in Eq. 18 projects the exchange rate in period $t+1$ as an extrapolation of the past exchange rate $\left(s_{t-1}\right)$ using the equilibrium nominal depreciation $\left(\Delta \bar{s}_{t}\right)$. The term $\Delta \bar{s}_{t}$ is the change in the exchange rate consistent with the long-term economic fundamentals represented by the domestic and foreign inflation targets and the equilibrium real exchange rate depreciation (in line with Purchasing Power Parity).

\section{Fiscal policy}

The model includes a simplified fiscal policy block, which features a standard debt accumulation dynamics:

$$
b_{t}=d_{t}^{a n n}+b_{t-4} \cdot \exp \left(-\frac{\Delta^{4} n y_{t}}{100}\right)+\varepsilon_{t}^{b}
$$

Here, the debt $b_{t}$ (expressed as debt to GDP ratio) depends on the previous year debt $b_{t-4}$, the year-on-year nominal GDP growth $\Delta^{4} n y_{t}$, and the annual overall fiscal deficit $d_{t}^{a n n}$ (which consists of primary deficit plus interest payments).

In the model, the decision-set for the fiscal authorities consists of three policy choices:

- A decision about a path for the debt target (which converges in the long run to a calibrated steady-state level of debt; see later);

- A choice of a level of structural deficit;

- A decision about ad-hoc discretionary changes in overall deficit.

By making decision about these three variables policymakers can adjust their fiscal policy strategies.

Decision 1: path for debt target. Fiscal authorities can make decision about the desired path for and a long-term level of the debt target, $b_{t}^{\text {tar }}$ :

$$
b_{t}^{\text {tar }}=C_{b t a r} \cdot b_{t-1}^{\text {tar }}+\left(1-C_{b t a r}\right) \cdot b_{s s}+\varepsilon_{t}^{b t a r}
$$


Decision 2: level of structural deficit. In every period fiscal policy decides about the level of structural deficit $\left(s d_{t}\right)$. Over time, structural deficit is assumed to slowly converge to a long-term sustainable deficit consistent with the debt target $\left(s d_{t}^{\text {tar }}\right)$.

$$
s d_{t}=C_{s d} \cdot s d_{t-1}+\left(1-C_{s d}\right) \cdot s d_{t}^{t a r}+\varepsilon_{t}^{s d}
$$

Convergence of $s d_{t}$ to $s d_{t}^{\text {tar }}$ assumes systematic fiscal policy which aims at keeping structural deficits close to the sustainable level. However, in any given period, fiscal authority may choose to alter the trajectory of structural deficits by ad-hoc adjustments through $\varepsilon_{t}^{s d}$.

Long-term sustainable deficit $\left(s d_{t}^{\text {tar }}\right)$ is derived from the process for the targeted debt:

$$
b_{t}^{\text {tar }}=s d_{t}^{\text {tar,ann }}+b_{t-4}^{\text {tar }} \cdot \exp \left(-\frac{E_{t} \Delta^{4} n y_{t+4}}{100}\right)
$$

Compared to the debt dynamics equation, here actual growth of nominal GDP is replaced by the expected growth $\left(E_{t} \Delta^{4} n y_{t+4}\right)$ to allow for the possibility of running higher current fiscal deficits in anticipation of higher future GDP growth. In other words, given the target debt level $\left(b_{t}^{t a r}\right)$, better prospects for future nominal income growth lead to higher long-run sustainable structural deficits $\left(s d_{t}^{t a r}\right)$, as fiscal policy may afford being more expansionary because past debt will be reduced by higher expected GDP growth.

At the same time, although sustainable deficits are such that keep the debt on the targeted level once it is attained, they however do not guarantee that the debt target will be achieved if the initial level of debt is above (or below) the target.

Decision 3: discretionary changes in overall deficit. Overall deficit is another policy choice variable in the model:

$$
d_{t}=s d_{t}-C_{1 d} \cdot \hat{y}_{t}-C_{2 d} \cdot b_{t}^{d e v}+\varepsilon_{t}^{d}
$$

It deviates from a structural deficit by: (i) the effect of automatic stabilizers (i.e. cyclical deficit $-C_{1 d} \hat{y}_{t}$ ); (ii) a transitory deviation from debt target $-C_{2 d} b_{t}^{\text {dev }}$ (to help achieve debt convergence to the target, a prudent fiscal policy will adjust deficits more aggressively if the actual debt deviates too far from the target); and (iii) an overall deficit shock $-\varepsilon_{t}^{d}$ (to provide room for a temporary fiscal discretion, e.g. pre-elections spending).

Fiscal impulse. Fiscal impulse is an indicator of added stimulus of budgetary policies on economic activity and enters the IS curve. Contrary to the classical approximation of the fiscal impulse as a change in cyclically adjusted fiscal balances, we define it in the model as the sum of all discretionary components of the fiscal policy decisions:

$$
\operatorname{fimp}_{t}=C_{\text {fimp }} \cdot \varepsilon_{t}^{b t a r}+\varepsilon_{t}^{s d}+\varepsilon_{t}^{d}
$$


We believe that this definition captures better the discretionary nature of adjustments in the fiscal behavior, which de facto constitute a fiscal stimulus.

\section{Parametrization of the Model And Model Properties}

\section{A. Calibration}

The current parametrization of the model is based on calibration, a practice which is widely adopted for this type of semi-structural model (Berg et al. 2006a and 2006b). The model parameters are calibrated using various methods (to be discussed in detail in the following sections). The exercise is generally set in such a way as to satisfy macroeconomic theory, reflect stylized facts of Japan's economy, and meet the requirement for satisfactory forecasting properties.

The final model calibration is typically a product of numerous iterations. The process starts by setting an initial calibration (usually using similar models as a reference point), and then refining it through a series of iterative steps, including the assessment of deterministic and stochastic properties of the model, its convergence characteristics, the goodness of fit, desired simulation properties, etc. We generally identify several groups of parameters and use different techniques to calibrate parameters in each of the groups. For instance,

- the steady state values are typically calibrated using either historical averages (e.g. using average GDP growth over historical period as a steady state for output growth in the model), official policy objectives (e.g. for inflation target), or forward-looking expert assessment (e.g. for medium-term equilibrium real interest rate);

- the parameters in structural equations are generally set in a way to satisfy a reasonable/parsimonious mixture of three conditions: (i) the model-based estimation of unobserved variables on the history should reflect desired stylized facts (e.g. a Kalmanfiltered output gap should be negative in the periods of economic downturn), (ii) the simulation properties of the model should be consistent with macroeconomic theory (e.g. model impulse responses should be such that inflation increases in response to a demand shock), (iii) the convergence characteristics of the model should be satisfactory for a medium-term forecasting (e.g. the model simulations should not be too "wavy");

- the coefficients in non-structural equations are calibrated to satisfy the observed data and ensure reasonably smooth trends;

- the standard deviations of shocks are calibrated to match the observed variance in the data.

In calibrating the Japan model we primarily focused on matching the stylized facts, observed data, and policy developments in the period since 2013 , when the BoJ officially announced an inflation targeting framework and the Government of Japan launched the three-pronged Abenomics policy program. In Appendix II, we discuss the calibration of selected parameters in some detail. 


\section{B. Impulse Response Functions}

In this section we assess the dynamic properties of the model by analyzing impulse response functions (IRFs). Specifically, we examine the responses of the variables to selected identified shocks and evaluate the corresponding monetary policy reaction.

An impulse response function shows the impact of an individual shock on variables in the model. It is an important tool to gauge the dynamic properties and the monetary transmission channels of the model and inform the model's calibration.

The reaction of monetary policy to a particular shock would be different depending on whether it is constraint by the effective lower bound (ELB) or is able to act at full discretion (i.e. in "normal times"), and subsequently, the dynamics of the economy would differ too in these two states.

Therefore, we will discuss IRFs conditional on the state of the economy at the time when a shock is realized. Specifically,

- to analyze the impulse responses in normal times, we use a model's steady state as an initial condition (i.e. all variables are assumed to be at their calibrated steady state values prior to the unexpected disturbance, and we examine the dynamics of their return to these steady states following the disturbance);

- to analyze impulse responses at the ELB (where the lower bound is set at zero percent), we start from the actual state of the Japan's economy in 2018Q4 (as estimated using the Kalman filter) and examine the difference in convergence of the economy to a calibrated steady state: (i) in the absence of any disturbances ("benchmark simulation"), and (ii) following a particular shock ("shock-induced simulation").

\section{Responses to a cost-push shock}

The system is hit by a one percent core inflation cost-push shock, which increases overall inflation on impact in the model (see Figure 1).

In normal times, the central bank reacts to expected inflationary pressures by raising the policy interest rate, often to prevent the second-round effects of the price hike. Increased domestic interest rates attract foreign capital and cause local currency to appreciate. Higher domestic borrowing costs and stronger exchange rate affect negatively the aggregate domestic demand. As the output drops below potential it further eases the inflationary pressures.

At the ELB, if inflation is below the target (as has been the case for Japan), the cost-push shock could be a blessing for a monetary policy. A central bank would usually choose to fully accommodate the impact of the shock, and instead of preempting the second-round effects and the rise in inflation expectations, it would actually count on and encourage them. In the model, this is realized through the policy rate remaining at the ELB until sufficient build-up of inflation inertia is realized. Compared to the normal times when the effect of the shock on inflation is all but gone in eight quarters, at the ELB, it is allowed to persist for 
longer (see grey bars on the subplots with inflation on Figure 1). When compared to a benchmark simulation, the exit from ELB following a cost-push shock happens earlier.

Figure 1. Impulse Response Functions in Response to a Cost-push Shock
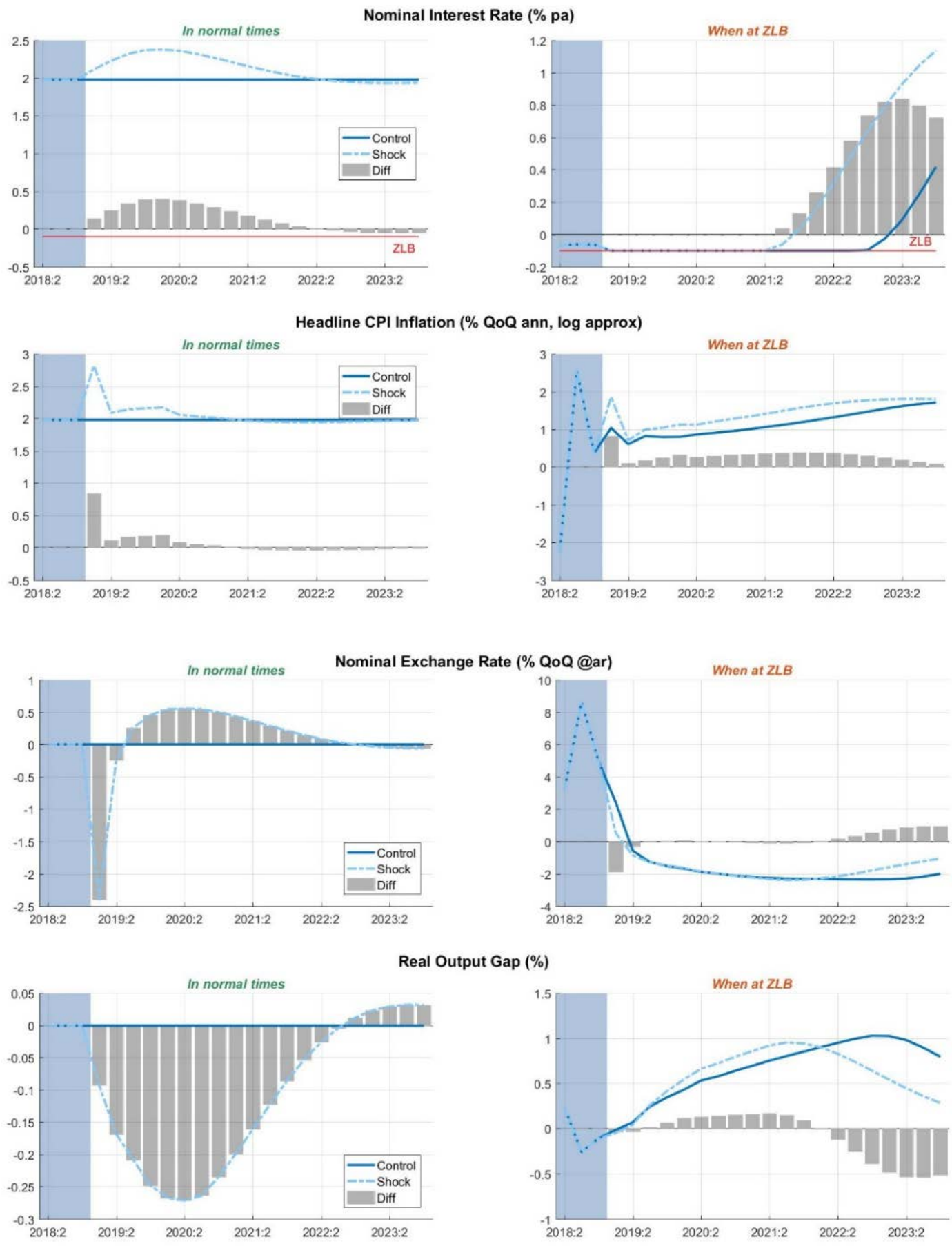


\section{Responses to a temporary negative oil price shock ${ }^{11}$}

The world oil prices unexpectedly drop by ten percent due to temporary factors. Given an immediate pass-through from world oil prices to domestic energy prices in the model, the latter drop on impact brings down overall domestic inflation and exerts downward pressure on the inflation expectations (see Figure 2).

\section{Figure 2. Impulse Response Functions in Response to a Negative Oil Price Shock}
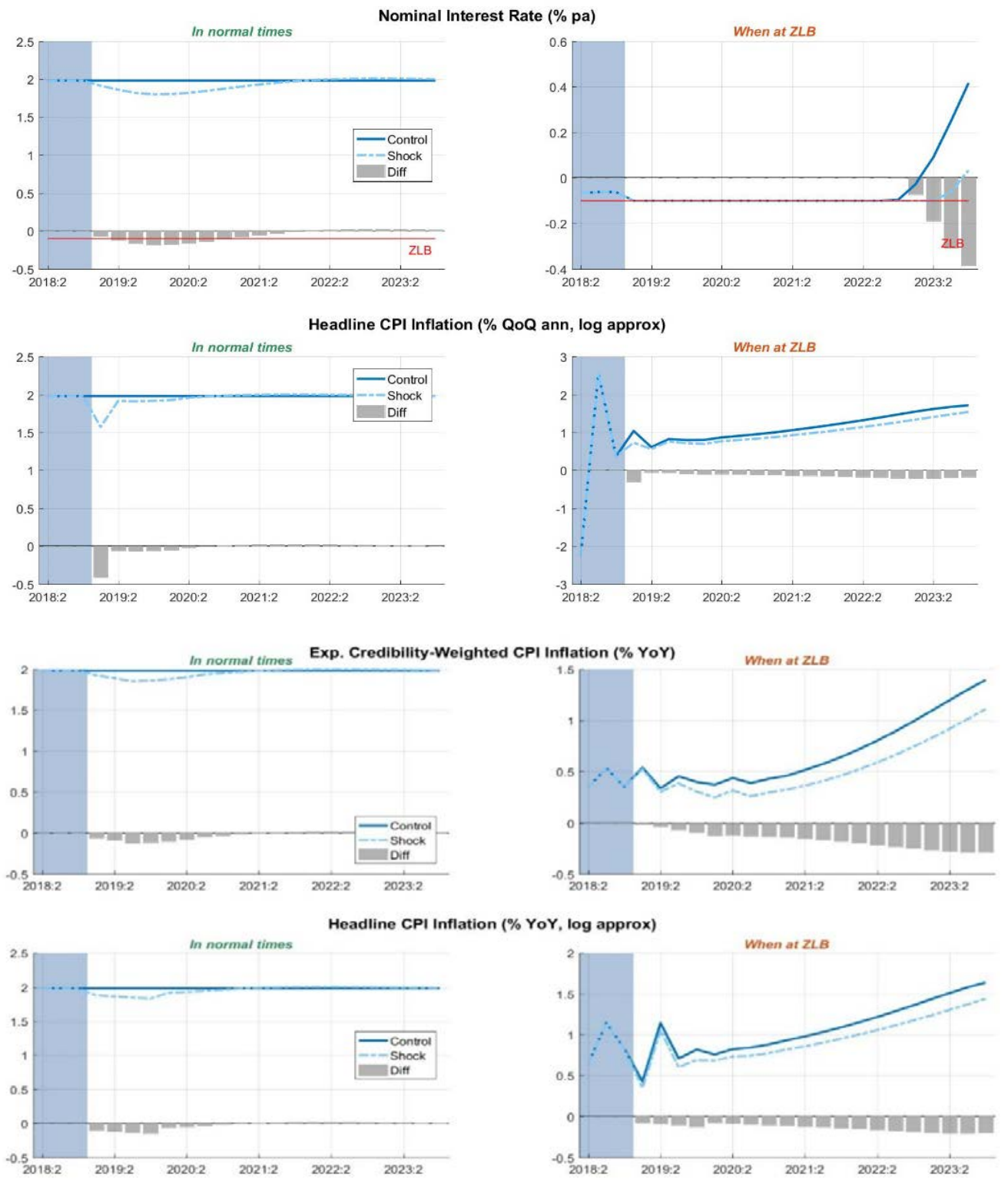

${ }^{11}$ Volatility of energy prices has been one of the key drivers of (headline) inflation dynamics during the Abenomics period. For instance, a sharp fall in oil prices resulted in six consecutive months of negative headline inflation in 2016. 
In normal times, the central bank reacts by cutting the policy rate to counteract the expected negative impact of the decline in inflation expectations and re-anchor them back at the inflation target. As domestic interest rates decrease, the expanding economic activity and weaker exchange rate stimulate inflation recovery (through demand and import channels, respectively).

At the ELB, as monetary policy actions are constrained by the effective lower bound on interest rates, nothing prevents a decline in inflation and inflation expectations. Although the negative oil price shock is temporary in nature, its effects persist for a prolonged period, as evidenced by inflation being permanently lower on the forecast horizon compared to the benchmark simulation (see Figure 2). ${ }^{12}$ This further delays the ELB unwinding date.

\section{Responses to a discretionary fiscal impulse}

A fiscal policy initiative looks to increase structural deficit by one percentage point of GDP. This increase constitutes a fiscal impulse to the economy and boosts aggregate demand. Intensified demand subsequently passes through into prices and inflation rises.

In normal times, to ensure that inflation expectations remain anchored, the central bank tightens monetary policy. The system stabilizes as demand pressures ease and inflation converges back to the target.

At the ELB, as monetary policy stays put with unchanged interest rates, the fiscal stimulus has more significant and prolonged demand effects (see Figure 3 ). In this reality the exit from the ELB is possible at an earlier stage compared to the benchmark simulation as inflation and inflation expectations are boosted by higher demand over the medium term.

\footnotetext{
12 Some recent empirical studies suggest that negative supply shocks are contractionary even under the zero lower bound (Garin et al. 2019 and Wiedland 2019).
} 
Figure 3. Impulse Response Functions in Response to a Discretionary Fiscal Impulse
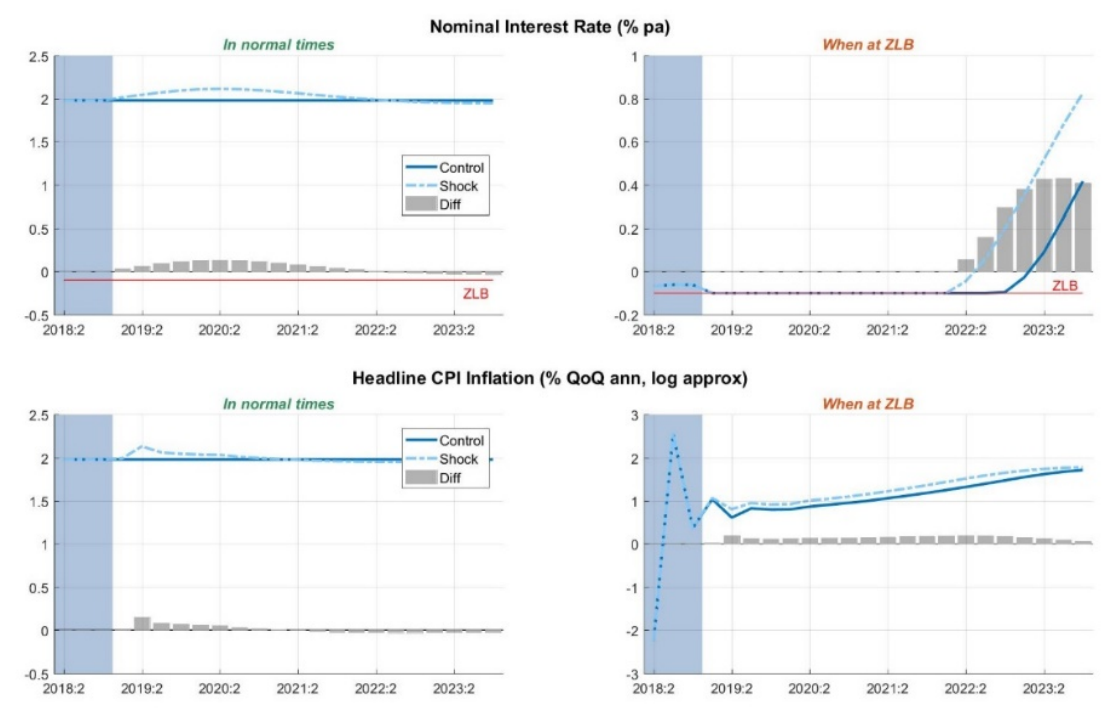
Figure 3. Impulse Response Functions in Response to a Discretionary Fiscal Impulse (concluded)
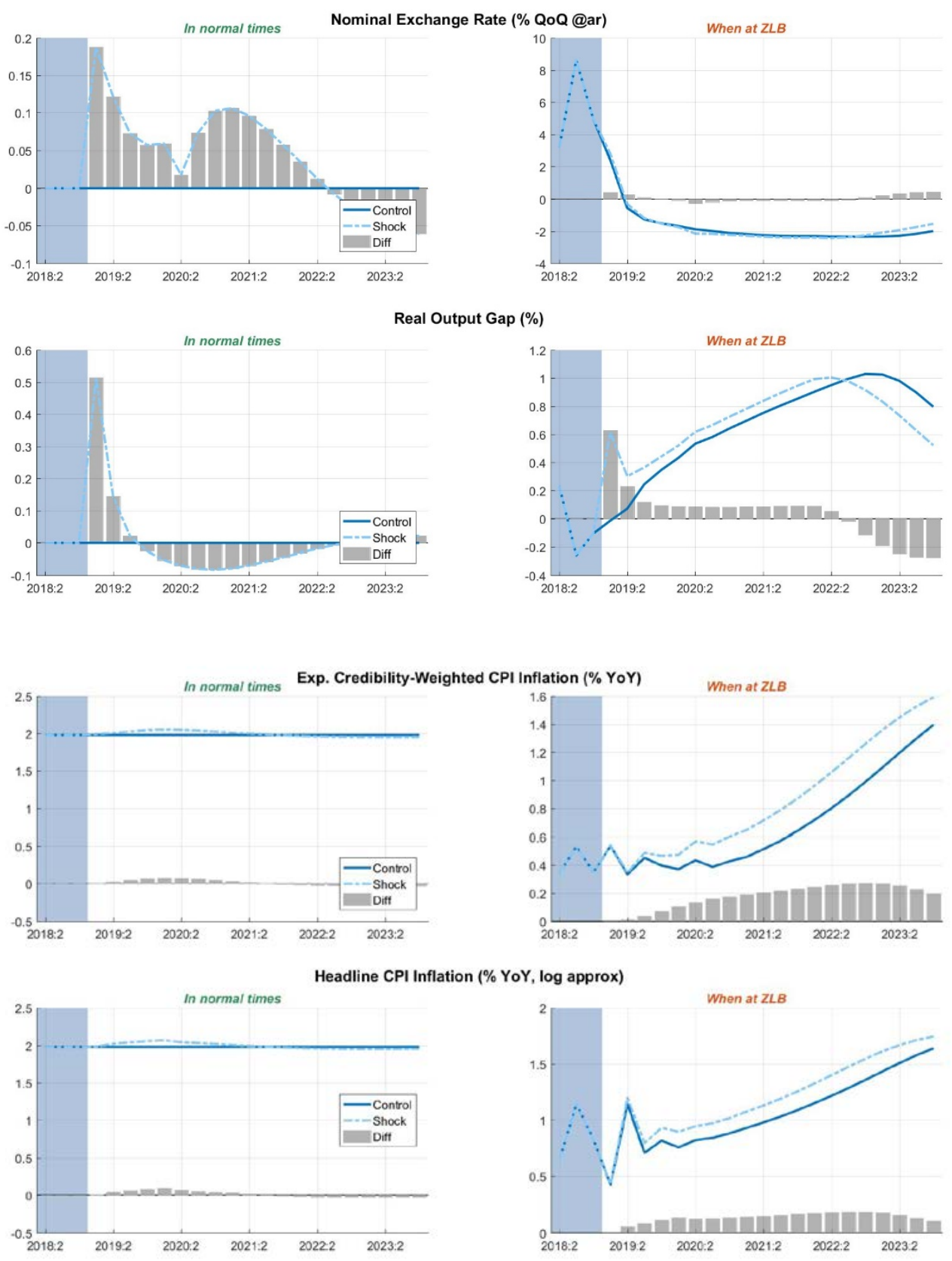

\section{Results}

In this section, we discuss the projection results shown for the baseline scenario and alternative scenarios. In all scenarios, we limit fiscal policy reactions to be only through the fiscal impulse, while assuming no role for structural reforms to highlight the role of monetary 
policy alone in achieving the inflation target. ${ }^{13}$ The baseline assumes an inflation-targeting central bank with imperfect credibility. Additionally, four alternative scenarios are considered: (1) a perfectly credible central bank; (2) a central bank with imperfect credibility and a temporary sharp increase in sovereign risk premium; (3) a central bank with imperfect credibility and a temporarily sharp appreciation of the Japanese yen; and (4) a central bank with imperfect credibility and a temporary decrease in world oil prices.

\section{A. Baseline Results}

The model's baseline scenario assumes a central bank with imperfect credibility. The historical output gap is consistent with the IMF staff's estimated output gap, published in the World Economic Outlook. Under this scenario, headline and core inflation will gradually rise towards the target over the medium-term. However, it is projected to stay under the target. Activization in domestic real activity is required to generate the inflationary pressures (Figure 4).

Figure 4. Baseline Projections for CPI inflation and Real GDP Growth
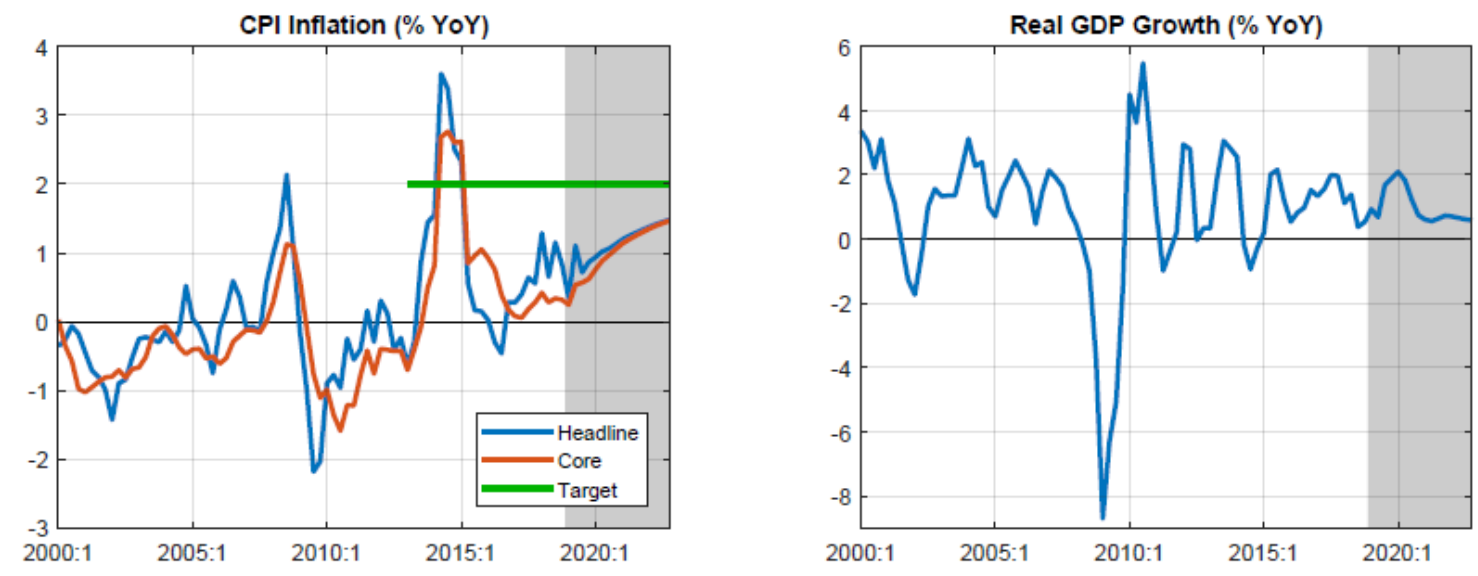

The real GDP level has to be above its trend, generating a positive output gap (Figure 5). Looking at the decomposition of the output gap projection, a positive output gap will be generated by accommodative monetary policy, resulting in a negative real interest rate gap and a negative real effective exchange rate gap (Figure 6).

\footnotetext{
${ }^{13}$ To understand the combined effects of fiscal, monetary policy and structural reforms on growth and inflation with a declining population, see Colacelli and Fernandez-Corugedo (2018).
} 
Figure 5. Baseline Projections for Real GDP and Real Output Gap
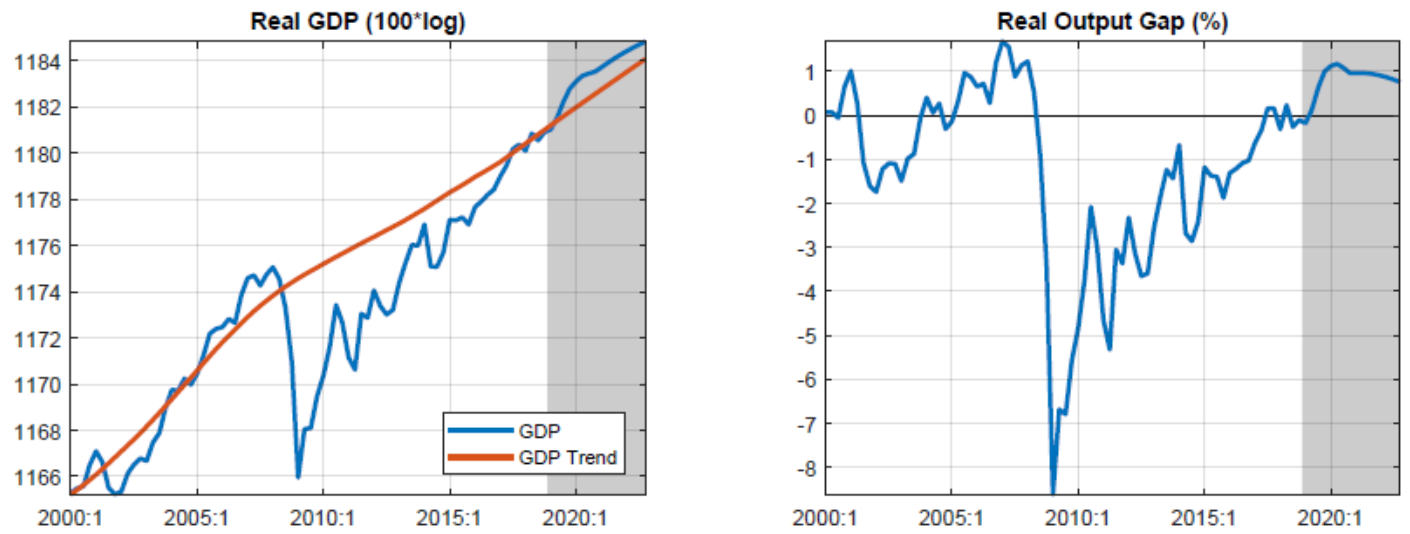

Figure 6. Decomposition of Real Output Gap

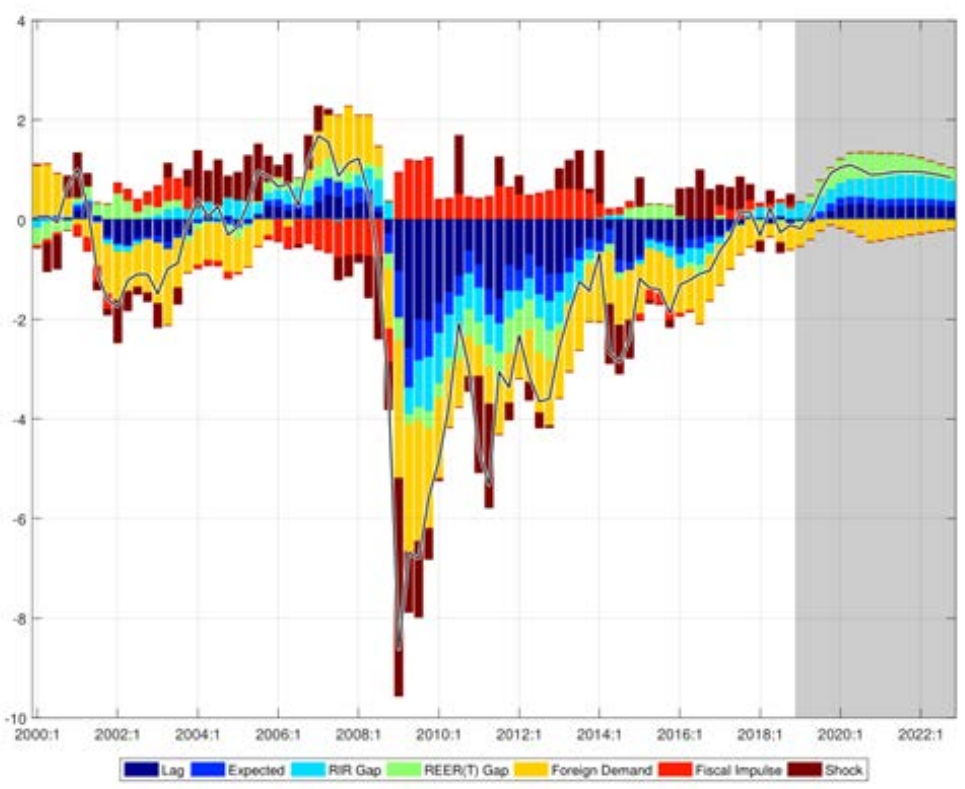

Headline inflation is expected to remain below the target. An increase in headline inflation is driven mainly by the rise in core inflation, as the contributions from food and energy prices are assumed to be roughly constant on average over the projection horizon (Figure 7 and Figure 8). As for the core inflation, the real marginal costs (proxied by a combination of output gap and real effective exchange rate gap) are the key driver of inflation. As inflation pressure builds up and credibility stock accumulates, inflation expectations recover contributing to further inflation increases. 


\section{Figure 7. Baseline: Decomposition of Headline Inflation}

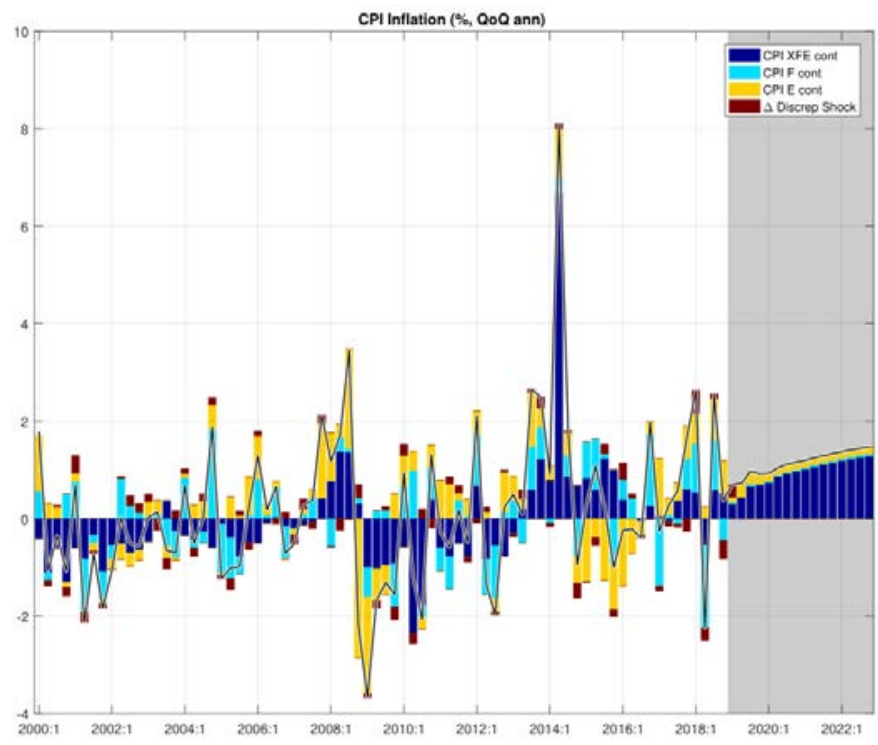

Figure 8. Baseline: Decomposition of Core Inflation

CPI XFE Inflation (\% QoQ, log approx)

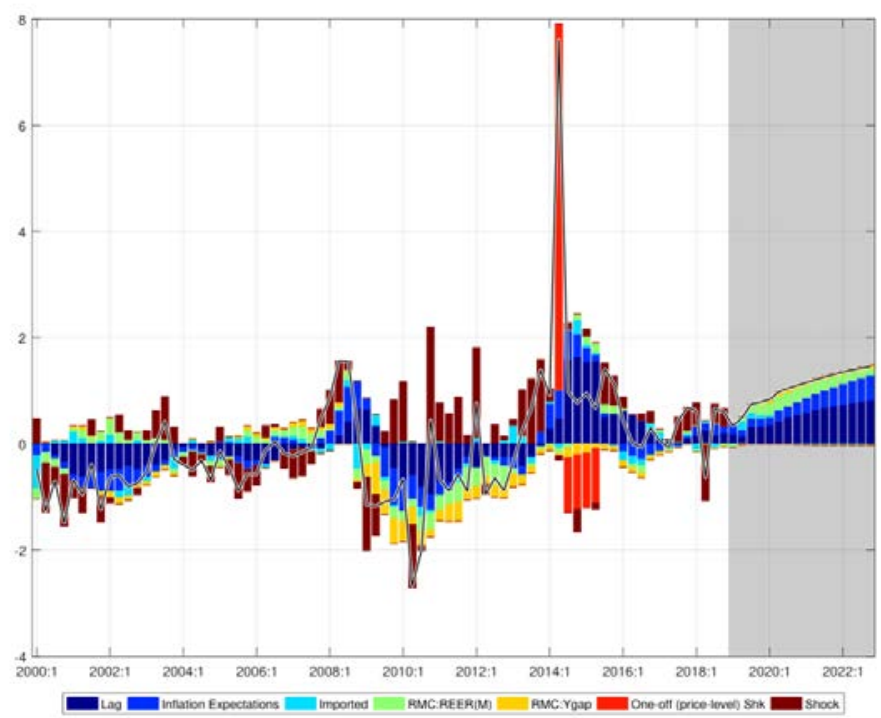

Accommodative monetary policy provides the necessary boost to growth by keeping both the real interest rate and exchange rate below trend. In the following chart (Figure 9), the nominal interest rate remains stuck at the effective lower bound (floor) for several quarters before the conditions become conducive enough for a rate increase. However, with an increase in inflation, real interest rate remains below zero.

So far, we have focused on the 'central' projection, which does not necessarily take into consideration uncertainty and risks around these projections. Fan charts are a useful tool to 
quantify the likelihood of attaining policy objectives. Following the work by Blix and Sellin (1998), we allow for the asymmetry of risks around the central projections by using a twopiece normal distribution.

Under current policies with imperfect credibility of the central bank, there is only a 16 percent likelihood that headline CPI inflation will reach 2 percent by the end of 2019Q4, according to fan chart analysis (Figure 10). For core inflation, the probability decreases to 6 percent, as the contribution to uncertainty from energy and food price shocks is relatively high. By the end of the projection horizon (2023Q4), headline and core inflation will reach the 2 percent target with a likelihood of 37 and 36 percent, respectively (Figure 11 and Table 1). The risk of deflation by the end of 2023Q4 for headline inflation and core inflation is about 35 percent each (Table 1).

Figure 9. Baseline: Nominal and Real Interest Rate
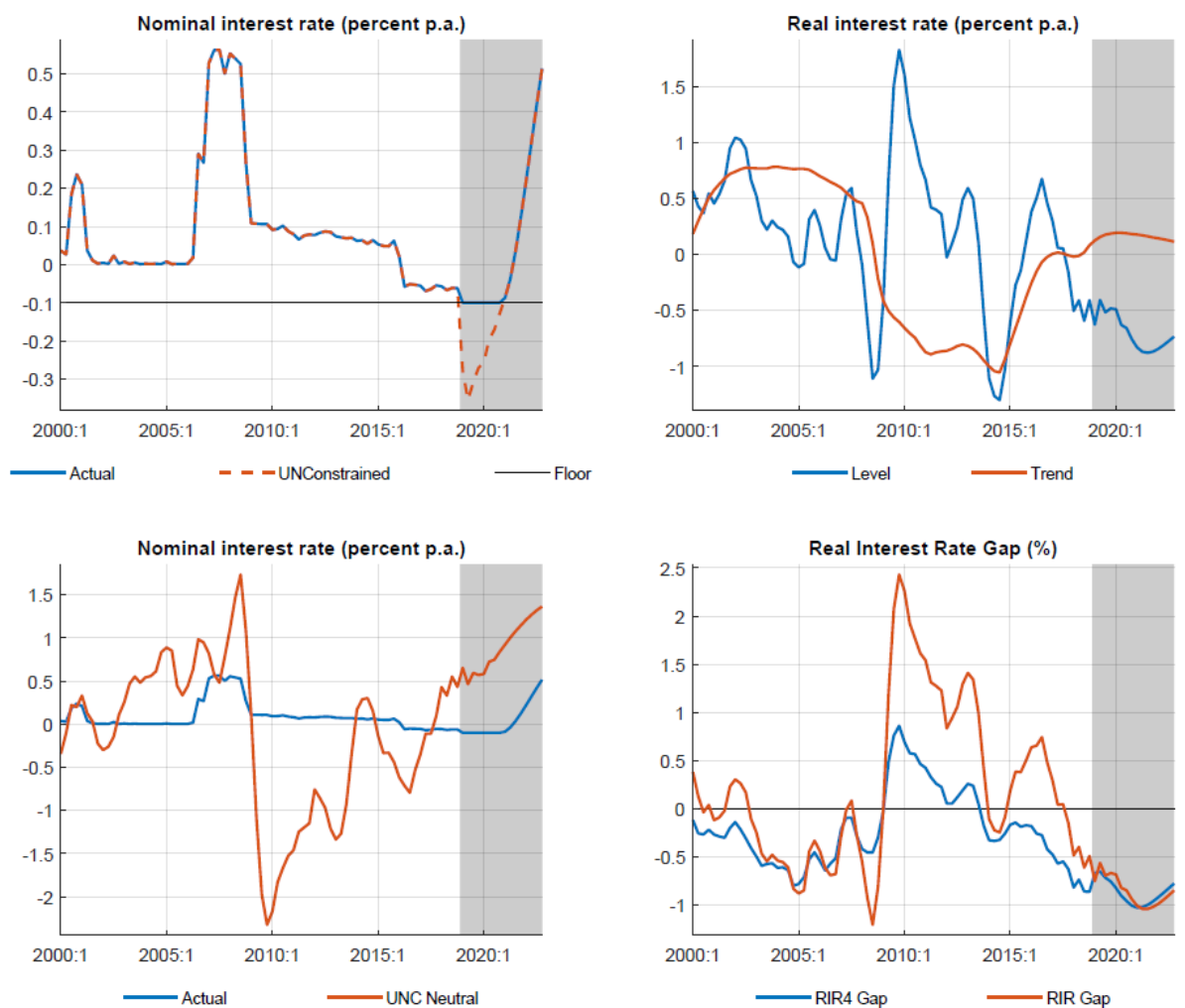
Figure 10. Baseline: Fan Charts for Headline and Core CPI Inflation
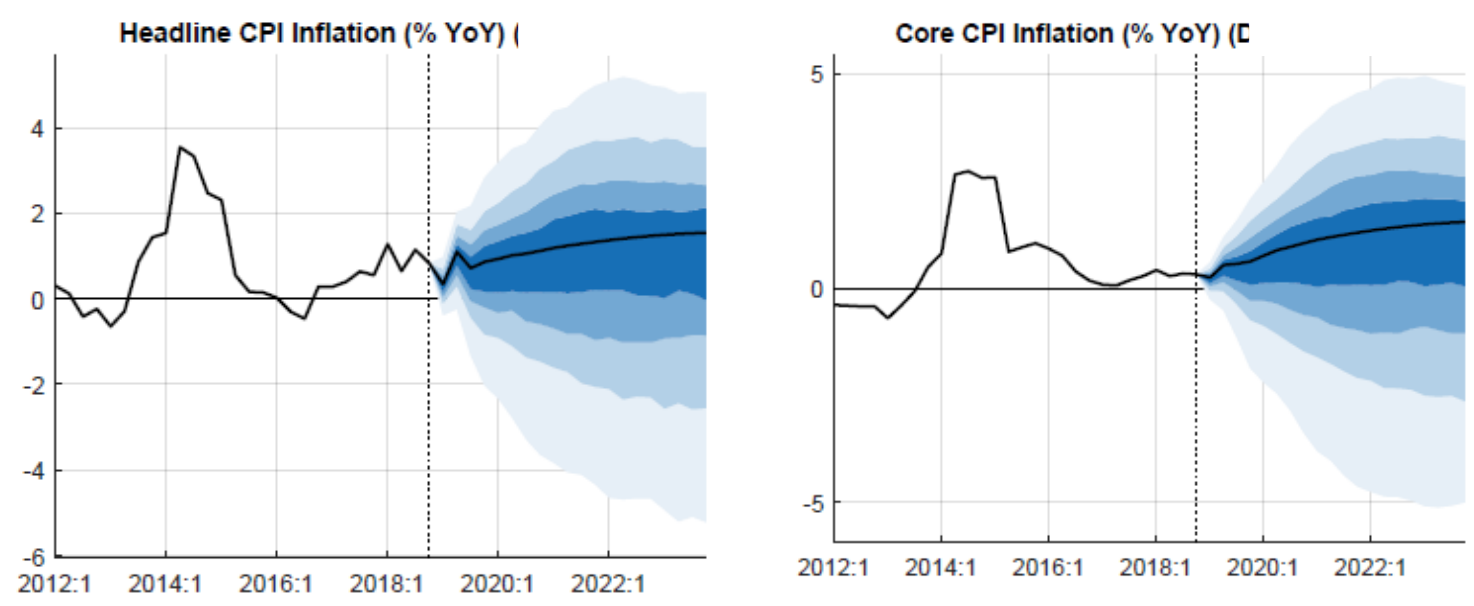

$90 \%$

$70 \%$

$50 \%$

$30 \%$ Confidence Interval

Figure 11. Baseline: Fan Charts for Real GDP Growth and Unemployment Rate
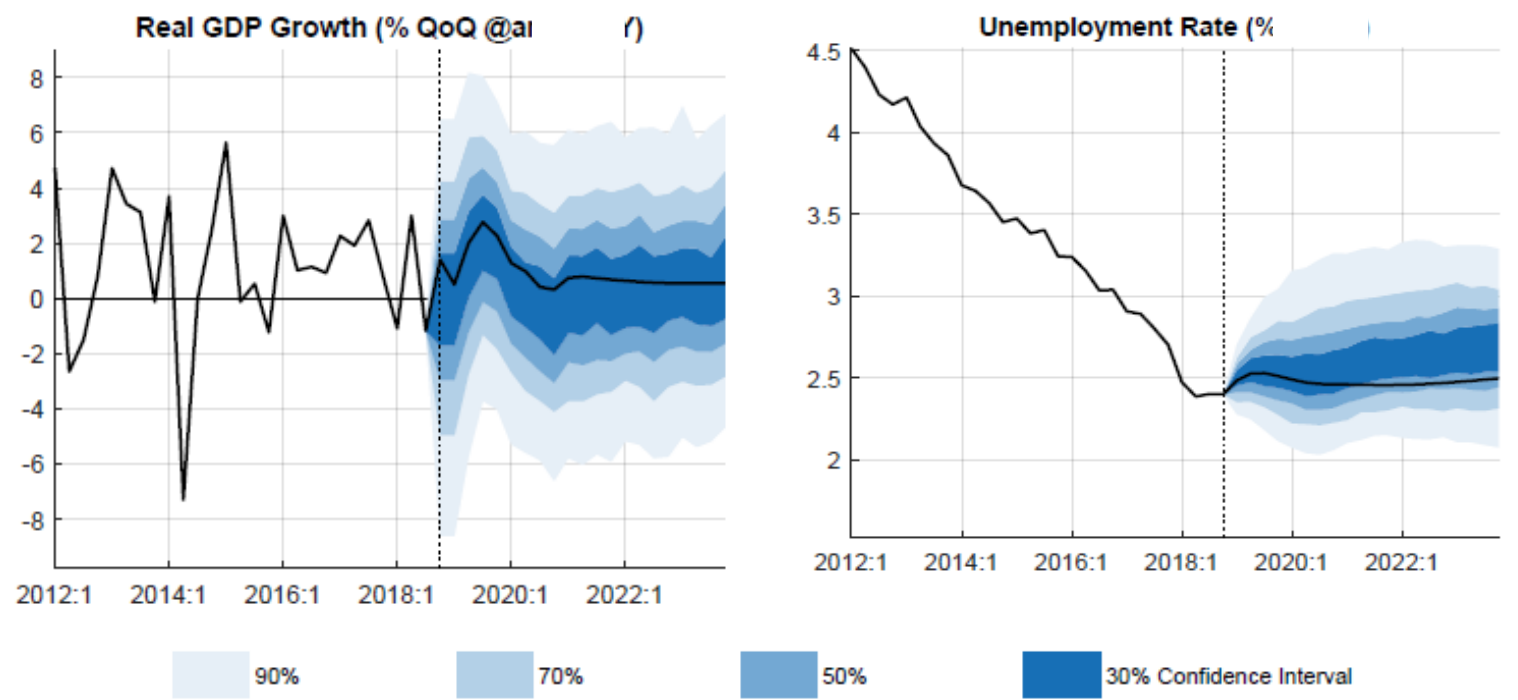

\section{B. Scenarios}

In this section, we explore probabilities of achieving policy objectives under several alternative scenarios. Four scenarios are considered: (1) a central bank with perfect credibility; (2) an imperfectly credible central bank with a sovereign risk premium shock; (3) an imperfectly credible central bank with a temporary yen appreciation, and (4) an imperfectly credible central bank with a decrease in world oil prices.

Table 1 summarizes the results for each scenario. Scenario 1 assesses the likelihood of achieving the price stability target with a perfectly credible central bank. Here, the 
probability of headline and core CPI inflation reaching the 2 percent target over the mediumterm rises to 44 and 45 percent, respectively. The likelihood of deflation (negative headline CPI inflation) is reduced from about 35 percent under the baseline scenario to about 27 percent. Scenarios 2 to 4 consider the cases of adverse shocks to inflation dynamics. Adverse shock scenarios reduce the likelihood of reaching the target to below 35 percent, while raising the likelihood of deflation.

Central bank credibility. Credibility is an important component of attaining the policy target. Under scenario 1, the central bank has perfect credibility, generating higher likelihood of reaching 2 percent inflation target over the medium-term. Even for perfectly credible central banks, accommodative monetary policy is needed to generate inflationary pressures to support a positive real output gap. However, the size of the output gap needed with a credible central bank is smaller than that is needed with an imperfectly credible central bank. In other words, if a central bank is credible, ceteris paribus, less accommodation is required to generate the same likelihood of achieving the inflation target (Figure 12).

\section{Table 1. Comparison Across Different Scenarios}

\begin{tabular}{|l|c|}
\hline & $\begin{array}{c}\text { Probability of headline inflation reaching the 2 } \\
\text { percent target in 2023Q4 (in percent) }\end{array}$ \\
\hline Baseline & 37.3 \\
Scenario 1. Perfect Credibility & 43.6 \\
Scenario 2. Baseline + Sovereign Risk Premium & 33.3 \\
Scenario 3. Baseline + Yen Appreciation & 32.1 \\
Scenario 4. Baseline + Low Oil Price Shock & 33.1 \\
\hline
\end{tabular}

\begin{tabular}{|l|c|}
\hline & $\begin{array}{c}\text { Probability of core inflation reaching the 2 percent } \\
\text { target in 2023Q4 (in percent) }\end{array}$ \\
\hline Baseline & 35.5 \\
Scenario 1. Perfect Credibility & 45.2 \\
Scenario 2. Baseline + Sovereign Risk Premium & 35.5 \\
Scenario 3. Baseline + Yen Appreciation & 33.9 \\
Scenario 4. Baseline + Low Oil Price Shock & 32.9 \\
\hline
\end{tabular}

\begin{tabular}{|l|c|}
\hline & Probability of headline inflation being negative in \\
2023Q4 (in percent)
\end{tabular}

\begin{tabular}{|l|c|}
\hline & Probability of core inflation being negative in \\
2023Q4 (in percent)
\end{tabular}


Figure 12. Comparison of Scenarios: Credible vs. Imperfectly Credible Central Bank
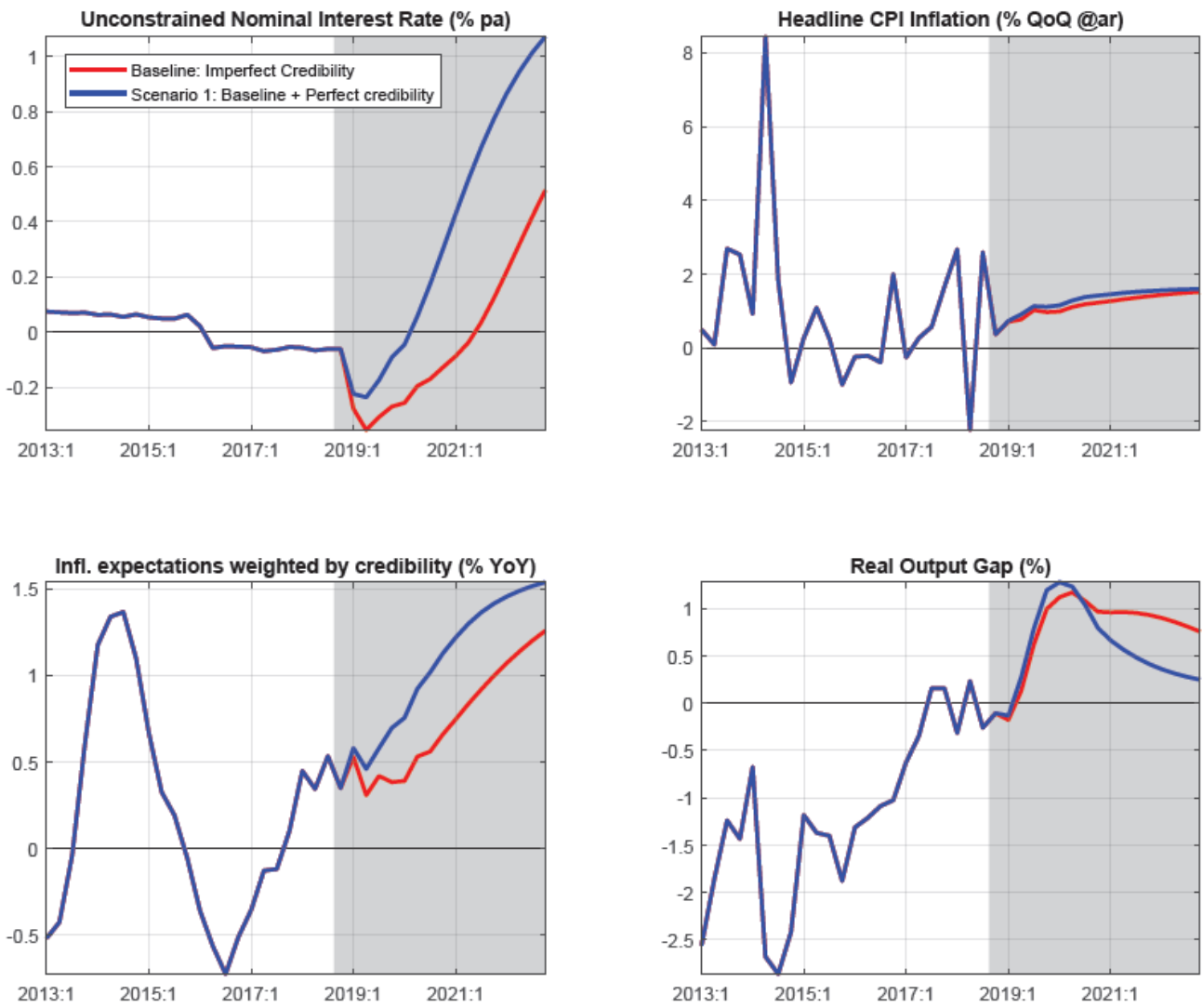

Given the backward-looking nature of inflation expectations in Japan, what can BoJ do to improve credibility and hence increase the likelihood of achieving the inflation target?

Broadly speaking there are two areas of improvements. First, because the accommodative stance is likely to be maintained for an extended period of time, there is a risk that mounting side-effects or competing objectives could negatively affect the public's confidence in BoJ's reflation commitment. Hence, it is crucial that the policy framework is flexible and sustainable enough to address these concerns. Second, the BoJ could further strengthen its communication framework. Among other measures, a clear explanation of the relationship between policy instruments and the outlook, including by publishing the BoJ staff baseline forecast with confidence bands, together with the underlying assumptions, would be one such option. ${ }^{14}$

\section{Conclusion}

Japan has endured a prolonged period of low inflation and low inflation expectations. Despite the Bank of Japan's efforts to reflate the economy since the launch of Abenomics in 2013,

\footnotetext{
${ }^{14}$ For specific recommendations see IMF (2016) Japan: Article IV Consultation-Staff Report (Box 3) and IMF (2017, 2018).
} 
achieving the price stability mandate over the medium-term is a challenging task for the central bank.

The paper discusses the construction of a model-based forecasting framework called the Forecasting and Policy Analysis System (FPAS) for Japan. To describe the Japanese economy, the model introduces two novel features which have not been introduced in previous FPAS models, the existence of an effective lower bound and endogenouslydetermined credibility of the central bank. Our FPAS model-based analysis confirms that the likelihood of reaching 2-percent inflation over the medium-term is quite low under the model's baseline scenario, and is even lower under alternative risk scenarios. Accommodative monetary policy is needed to boost demand to generate price pressures with a positive output gap over the medium-term. However, our analysis also highlights that monetary policy alone cannot ensure the achievement of the inflation target goal. A comprehensive policy package which encompasses other policy initiatives (such as fiscal policy and structural reforms) and promotes coordination among different policy measures (as recommended by IMF 2016, 2017, 2018), is necessary to increase the likelihood of reaching the inflation target.

This paper could benefit from future studies in the following areas. First, what could a central bank do to improve its credibility? The answers to this question would be critical for the policy makers. Second, another fruitful avenue for future research would be incorporate labor market dynamics and institutional aspects, such as labor market duality and wage-setting mechanisms. This will enrich our understanding of how labor market dynamics interact with and affect the transmission channel of monetary policy. 


\section{References}

Alichi, Ali, Huigan Chen, Kevin Clinton, Charles Freedman, Marianne Johnson, Ondra Kamenik, Turgut Kisinbay, and Douglas Laxton, 2009, "Inflation Targeting Under Imperfect Policy Credibility," IMF Working Paper 09/94 (Washington, International Monetary Fund).

Amarasekara, C., Anand, R., Ehelepola, K., Ekanayake, H., Jayawickrema, V., Jegajeevan, S., Kober, C., Nugawela, T., Plotnikov, S., Remo, A., Venuganan, P. and Yatigammana, R., 2018. An Open Economy Quarterly Projection Model for Sri Lanka. Staff Studies, 48(1), pp.21-66.

Anand, Rahul, Ding Ding and Volodymyr Tulin, 2014, "Food Inflation in India: The Role for Monetary Policy," IMF Working Paper, 14/178 (Washington, International Monetary Fund).

Argov, Eyal, David Rose, Philippe D. Karam, Natan P. Epstein and Douglas Laxton, 2007, "Endogenous Monetary Policy Credibility in a Small Macro Model of Israel," IMF Working Paper 07/207 (Washington, International Monetary Fund).

Benes, Jaromir, Kevin Clinton, Asish George, Pranav Gupta, Joice John, Ondra Kamenik, Douglas Laxton, Pratik Mitra, G.V.Nadhanael, Rafael Portillo, Hou Wang, and Fan Zhang, 2017, "Quarterly Projection Model for India: Key Elements and Properties," IMF Working Paper 17/33 (Washington, International Monetary Fund).

Berg, Andrew, Philippe D. Karam, and Douglas Laxton, 2006a, “A Practical Model-Based Approach to Monetary Policy Analysis, Overview," IMF Working Paper 06/080 (Washington, International Monetary Fund).

Berg, Andrew, Philippe D. Karam, and Douglas Laxton, 2006b, "Practical Model-Based Monetary Policy Analysis -A How-to Guide," IMF Working Paper 06/081 (Washington, International Monetary Fund).

Blix, Marten and Peter Sellin, 1998. "Uncertainty Bands for Inflation Forecasts," Sveriges Riksbank Working Paper No. 65.

Byron Botha \& Shaun de Jager \& Franz Ruch \& Rudi Steinbach, 2017. "The Quarterly Projection Model of the SARB," Working Papers 8000, South African Reserve Bank.

Chen, Huigang, Kevin Clinton, Marianne Johnson, Ondra Kamenik and Douglas Laxton, 2009, "Constructing Forecast Confidence Bands During the Financial Crisis," IMF Working Paper 09/214 (Washington, International Monetary Fund).

Colacelli, Mariana and Emilio Fernandez-Corugedo, 2018, "Macroeconomic Effects of Japan's Demographics: Can Structural Reforms Reverse Them?” IMF Working Paper 18/248 (Washington, International Monetary Fund). 
Coats, Warren, Douglas Laxton, and David Rose, 2003, The Czech National Bank's

Forecasting and Policy Analysis System (Prague: Czech National Bank).

Fuhrer, Jeffery and Glenn Rudebusch, 2004, "Estimating the Euler Equation for Output," Journal of Monetary Economics, Vol 51 (6), pp. 1133-1153.

Fuhrer, Jeffrey, 2017. "Expectations as a Source of Macroeconomic Persistence: Evidence from Survey Expectations in a Dynamic Macro Model," Journal of Monetary Economics, Vol. 86, pp. 22-35.

Garin, J. R. Lester, and E. Sims, 2019. "Are Supply Shocks Contractionary at the ZLB? Evidence from Utilization-Adjusted TFP data," Review of Economics and Statistics, Vol 101 (1), pp.160-175.

Goodhart, Charles and Boris Hofmann, 2005, "The IS Curve and the Transmission of Monetary Policy: is there a puzzle?" Applied Economics, Vol 37(1), pp. 29-36.

Hirakata, N., K. Kan, A. Kanafuji, Y. Kido, Y. Kishaba, T. Murakoshi, and T. Shinohara, 2019, “The Quarterly Japanese Economic Model (Q-JEM): 2019 veresion,” Bank of Japan Working Paper Series, No. 19-E-7 (Tokyo, Bank of Japan).

Hong, Gee Hee and John Kandrac, 2018, “How Banks React to Negative Rates: Early Evidence from Japan” IMF Working Paper 18/11 (Washington, International Monetary Fund).

International Monetary Fund, 2013, Japan: 2013 Article IV Consultation, IMF Country Report 13/253 (Washington: International Monetary Fund).

International Monetary Fund, 2014, Japan: 2014 Article IV Consultation, IMF Country Report 14/236 (Washington: International Monetary Fund).

International Monetary Fund, 2015, Japan: 2015 Article IV Consultation, IMF Country Report 15/197 (Washington: International Monetary Fund).

International Monetary Fund, 2016, Japan: 2016 Article IV Consultation, IMF Country Report 16/267 (Washington: International Monetary Fund).

International Monetary Fund, 2017, Japan: 2017 Article IV Consultation, IMF Country Report 17/242 (Washington: International Monetary Fund).

International Monetary Fund, 2018, Japan: 2018 Article IV Consultation, IMF Country Report 18/333 (Washington: International Monetary Fund).

Kaihatsu, Sohei and Jouchi Nakajima, 2015, "Has Trend Inflation Shifted? An Empirical Analysis with a Regime-Switching Model," Bank of Japan Working Paper Series No. 15-E-3 (Tokyo, Bank of Japan). 
Kamada, Koichiro, Jouchi Nakamura and Shusaku Nishiguchi, 2015, "Are Household Inflation Expectations Anchored in Japan?" Bank of Japan Working Paper Series No. 15-E-8 (Tokyo, Bank of Japan).

Kanna, Prakash and Selim Elekdag, 2009, "Incorporating Market Information into the Construction of the Fan Chart," IMF Working Paper 09/178 (Washington, International Monetary Fund).

Nakazono, Yoshiyuki, 2016, "Inflation Expectations and Monetary Under Disagreements," Bank of Japan Working Paper Series, 16-E-1 (Tokyo, Bank of Japan).

Obstfeld, Maurice, Kevin Clinton, Ondra Kamenik, Douglas Laxton, Yulia Ustyugova, and Hou Wang, 2016, "How to Improve Inflation Targeting in Canada," IMF Working Paper 16/192 (Washington, International Monetary Fund).

Razi, Ahmad and P Ling Loke, 2017, "Fan Chart: The art and science of communicating uncertainty," IFC Bulletins chapters, Statistical Implications of the New Financial Landscape, Volume 43, Bank for International Settlements.

Svensson, Lars, 2014, “Forward Guidance,” NBER Working Paper Series No. 20796.

Wieland, Johannes, 2019, “Are Negative Supply Shocks Expansionary at the Zero Lower Bound?" Journal of Political Economy, 127 (3), pp. 973-1007. 


\section{Appendix I. Evolution of the Bank of Japan's Monetary Policy During Abenomics}

\begin{tabular}{|c|l|}
\hline Timeline & \multicolumn{1}{c|}{ Monetary Policy Framework } \\
\hline January 2013 & Price Stability Target of 2 percent \\
\hline April 2013 & $\begin{array}{l}\text { Qualitative and Quantitative Easing (QQE) with annual JGB } \\
\text { purchases of ¥40 trillion }\end{array}$ \\
\hline October 2014 & $\begin{array}{l}\text { Qualitative and Quantitative Easing (QQE) with annual JGB } \\
\text { purchases of ¥80 trillion }\end{array}$ \\
\hline January 2016 & Introducing Negative Interest Rate Policy \\
\hline September 2016 & QQE with Yield Curve Control, Inflation-Overshooting Commitment \\
\hline
\end{tabular}

January 22, 2013: The "Price Stability Target" under the Framework for the Conduct of Monetary Policy

"The newly-introduced 'price stability target' is the inflation rate that the Bank judges to be consistent with price stability on a sustainable basis ... [T] he Bank sets the 'price stability target' at 2 percent in terms of the year on-year rate of change in the consumer price index (CPI) - a main price index."

April 4, 2013: Introduction of "Quantitative and Qualitative Monetary Easing"

"The Bank will achieve the price stability target of 2 percent in terms of the year-onyear rate of change in the consumer price index (CPI) at the earliest possible time, with a time horizon of about two years. In order to do so, it will enter a new phase of monetary easing both in terms of quantity and quality."

October 31, 2014: "Expansion of the Quantitative and Qualitative Monetary Easing"

"The Bank will conduct money market operations so that the monetary base will increase at an annual pace of about 80 trillion yen (an addition of about 10-20 trillion yen compared with the past)."

January 29, 2016: Introduction of "Quantitative and Qualitative Monetary Easing with a Negative Interest Rate"

"The Bank will apply a negative interest rate of minus 0.1 percent to current accounts that financial institutions hold at the Bank...[S]pecifically, the Bank will adopt a three-tier system in which the outstanding balance of each financial institution's current account at the Bank will be divided into three tiers, to each of which a positive interest rate, a zero interest rate, or a negative interest rate will be applied, respectively."

September 21, 2016: New Framework for Strengthening Monetary Easing: "Quantitative and Qualitative Monetary Easing with Yield Curve Control" 
"Based on these, with a view to achieving the price stability target of 2 percent at the earliest possible time, the Bank decided to introduce "QQE with Yield Curve Control" by strengthening the two previous policy frameworks mentioned above. The new policy framework consists of two major components: the first is "yield curve control" in which the Bank will control short-term and long-term interest rates; and the second is an "inflation-overshooting commitment" in which the Bank commits itself to expanding the monetary base until the year-on-year rate of increase in the observed consumer price index (CPI) exceeds the price stability target of 2 percent and stays above the target in a stable manner." 


\section{Appendix II. Calibration of Parameters}

\section{Aggregate Demand}

Coefficient estimates for the output gap equation and real monetary conditions index are reported in a table below:

$$
\begin{gathered}
\hat{y}_{t}=\beta_{1} \hat{y}_{t-1}+\beta_{2} \hat{y}_{t+1}+\beta_{3} R M C I_{t}+\beta_{4} \hat{y}_{t}^{*}+\beta_{5} f i m p_{t}+\varepsilon_{t}^{\hat{y}} \\
R M C I_{t}=\lambda \hat{r}_{t}+(1-\lambda)\left(-\hat{z}_{t}^{R E E R}\right)
\end{gathered}
$$

\begin{tabular}{|c|c|}
\hline Parameter & Estimates \\
\hline$\beta_{1}$ & 0.3 \\
\hline$\beta_{2}$ & 0.15 \\
\hline$\beta_{3}$ & 0.55 \\
\hline$\beta_{4}$ & 0.8 \\
\hline$\beta_{5}$ & 0.5 \\
\hline$\lambda$ & $\approx 0.82$ \\
\hline
\end{tabular}

The parameters in the aggregate demand equation depend to a large extent on the degree of inertia in the economy, the effectiveness of monetary policy transmission, and the openness of the economy. The effectiveness of monetary policy is shown by $\beta_{3} * \lambda$, while the openness of the economy is reflected in $\left(-\beta_{3} *(1-\lambda)\right)$. For Japan, the first estimate is around 0.45 and the latter is around -0.1 .

\section{Okun's Law}

Coefficient estimates for the Okun's law are reported in the table below:

$$
\hat{u}_{t}=\gamma_{1} \hat{u}_{t-1}+\gamma_{2} \hat{y}_{t}+\varepsilon_{t}^{\widehat{u}}
$$

\begin{tabular}{|c|c|}
\hline Parameter & Estimates \\
\hline$\gamma_{1}$ & 0.7 \\
\hline$\gamma_{2}$ & 0.05 \\
\hline
\end{tabular}

\section{Phillips Curve}

Coefficient estimates for the Phillips Curve are reported in the table below:

$$
\begin{gathered}
\pi_{t}^{\text {core }}=\alpha_{\text {core }} \pi_{t-1}^{\text {core }}+\left(1-\alpha_{\text {core }}\right) \pi_{t}^{E w}+\alpha_{2} \Delta \hat{z}_{t}^{R E E R}+\alpha_{3} r m c_{t}^{\text {core }}+\varepsilon_{t}^{\pi^{\text {core }}} \\
r m c_{t}^{\text {core }}=\alpha_{r m c} \hat{z}_{t}^{R E E R}+\left(1-\alpha_{r m c}\right) \hat{y}_{t-1} \\
\pi_{t}^{e n}=\alpha_{e n} \pi_{t-1}^{e n}+\left(1-\alpha_{e n}\right) \pi_{t}^{E w}+\alpha_{4} \Delta \hat{z}_{t}^{O I L}+\alpha_{5} \hat{z}_{t}^{O I L}+\varepsilon_{t}^{\pi^{e n}}
\end{gathered}
$$




$$
\pi_{t}^{f f}=\alpha_{f f} \pi_{t-1}^{f f}+\left(1-\alpha_{f f}\right) \pi_{t}^{E w}+\alpha_{6} \Delta \hat{z}_{t}^{F O O D}+\alpha_{7} \hat{z}_{t}^{F O O D}+\varepsilon_{t}^{\pi^{f f}}
$$

\begin{tabular}{|c|c|}
\hline Parameter & Estimates \\
\hline$\alpha_{\text {core }}$ & 0.6 \\
\hline$\alpha_{2}$ & 0.07 \\
\hline$\alpha_{3}$ & 0.12 \\
\hline$\alpha_{r m c}$ & $\approx 0.42$ \\
\hline$\alpha_{e n}$ & 0.2 \\
\hline$\alpha_{4}$ & 0.3 \\
\hline$\alpha_{5}$ & 0.2 \\
\hline$\alpha_{f f}$ & 0.05 \\
\hline$\alpha_{6}$ & 0.2 \\
\hline$\alpha_{7}$ & 0.05 \\
\hline
\end{tabular}

\section{Central Bank Credibility}

Coefficient estimates for the credibility-building mechanism are reported in the table below:

$$
\begin{gathered}
\pi_{t}^{E w}=\text { credib }_{t} \cdot E_{t} \pi_{t+1}^{\text {yearly }}+\left(1-\text { credib }_{t}\right) \cdot \pi_{t-1}^{\text {yearly }}+\text { bias }_{t}+\varepsilon_{t}^{\pi^{E w}} \\
\text { credib }_{t}=\alpha_{\text {cred }} \cdot \operatorname{credib}_{t-1}+\left(1-\alpha_{\text {cred }}\right) \cdot \xi_{t}^{\text {signal }}+\varepsilon_{t}^{\text {credib }} \\
\text { bias }_{t}=\beta_{\text {bias }} \cdot\left(\text { credib }_{t} \cdot \pi^{\text {tar }}+\left(1-\text { credib }_{t}\right) \cdot 0-\pi^{\text {tar }}\right)
\end{gathered}
$$

\begin{tabular}{|c|c|}
\hline Parameter & Estimates \\
\hline$\alpha_{\text {cred }}$ & 0.85 \\
\hline$\beta_{\text {bias }}$ & 0.3 \\
\hline
\end{tabular}

\section{Uncovered Interest Parity Conditions}

$$
s_{t+1}^{E}=\alpha_{U I P} \cdot E_{t} s_{t+1}+\left(1-\alpha_{U I P}\right) \cdot\left(s_{t-1}+2 \cdot \Delta \bar{s}_{t} / 4\right)
$$

\begin{tabular}{|c|c|}
\hline Parameter & Estimates \\
\hline$\alpha_{U I P}$ & 0.85 \\
\hline
\end{tabular}

\section{Fiscal Sector}

$$
\operatorname{fimp}_{t}=C_{f i m p} \cdot \varepsilon_{t}^{b t a r}+\varepsilon_{t}^{s d}+\varepsilon_{t}^{d}
$$

\begin{tabular}{|c|c|}
\hline Parameter & Estimates \\
\hline$C_{\text {fimp }}$ & 0.1 \\
\hline
\end{tabular}

